\title{
Comprehensive elaboration of the cGAS- STING signaling axis in cancer development and immunotherapy
}

\author{
Juyan Zheng ${ }^{1,2+}$, Junluan $\mathrm{Mo}^{3+}$, Tao Zhu ${ }^{1,2}$, Wei Zhuo ${ }^{1,2}$, Yueneng $\mathrm{Yi}^{4}$, Shuo Hu${ }^{5}$, Jiye Yin ${ }^{1,2}$, Wei Zhang ${ }^{1,2}$, \\ Honghao Zhou ${ }^{1,2}$ and Zhaogian Liu ${ }^{1,2^{*}}$ (D)
}

\begin{abstract}
Cellular recognition of microbial DNA is an evolutionarily conserved mechanism by which the innate immune system detects pathogens. Cyclic GMP-AMP synthase (cGAS) and its downstream effector, stimulator of interferon genes (STING), are involved in mediating fundamental innate antimicrobial immunity by promoting the release of type I interferons (IFNs) and other inflammatory cytokines. Accumulating evidence suggests that the activation of the cGAS-STING axis is critical for antitumor immunity. The downstream cytokines regulated by CGAS-STING, especially type I IFNs, serve as bridges connecting innate immunity with adaptive immunity. Accordingly, a growing number of studies have focused on the synthesis and screening of STING pathway agonists. However, chronic STING activation may lead to a protumor phenotype in certain malignancies. Hence, the CGAS-STING signaling pathway must be orchestrated properly when STING agonists are used alone or in combination. In this review, we discuss the dichotomous roles of the CGAS-STING pathway in tumor development and the latest advances in the use of STING agonists.
\end{abstract}

Keywords: CGAS-STING, Innate immunity, Type I interferon, STING agonists, Antitumor response, Cancer development

\section{Introduction}

The discovery of phagocytosis in 1883 advanced the understanding of innate immunity, the first line of host defenses against infection by various pathogens [1]. Protection against infection depends on patternrecognition receptors (PRRs), which recognize microbial products, coordinate antimicrobial defenses and activate

\footnotetext{
* Correspondence: zqliu@csu.edu.cn

†Juyan Zheng and Junluan Mo contributed equally to this work.

'Department of Clinical Pharmacology, Hunan Key Laboratory of

Pharmacogenetics, and National Clinical Research Center for Geriatric

Disorders, Xiangya Hospital, Central South University, Changsha 410008,

People's Republic of China

${ }^{2}$ Institute of Clinical Pharmacology, Engineering Research Center for applied

Technology of Pharmacogenomics of Ministry of Education, Central South University, Changsha 410078, People's Republic of China

Full list of author information is available at the end of the article
}

adaptive immunity [2]. Abnormal RNA or DNA, RNADNA hybridization and cyclic dinucleotides derived from microbes are usually considered pathogen-associated molecular patterns (PAMPs) [2, 3]. Cells associated with innate immunity recognize different microbial PAMPs through specific PRRs, thereby playing key roles in host resistance to microbial infection [4]. The pathways governing RNA recognition, such as retinoid acid inducible gene I (RIG-I)-like receptors, have been reviewed elsewhere and will not be covered herein. In the case of DNA recognition, one of the best known PRRs is Toll-like receptor 9 (TLR9), which senses extracellular CpG hypomethylated DNA that has entered the cytosol through the phagosome-lysosome system [5]. In addition, the AIM2like receptor (AIM2) inflammasome can be triggered after the entry of double-stranded DNA (dsDNA) into the 
cytosolic compartment, which induces the proteolytic maturation of proinflammatory cytokines (such as IL-1 $\beta$ and IL-18) and the activation of gasdermin D, leading to pyroptosis [6-9]. Nevertheless, the most notable PRR is cGAS, a direct cytosolic dsDNA sensor, which was identified by Dr. Chen's group in 2013 [10]. Once cGAS binds to dsDNA, the cGAS-STING pathway is activated to further induce the expression of type I IFNs and other inflammatory cytokines, thus triggering innate immune responses [11]. Mounting evidence suggests that cGASSTING signaling not only plays pivotal roles in the host defense against microbial infection but also modulates tumorigenesis. Hence, in this review, we summarize the mechanism of cGAS-STING activation and elaborate findings regarding its dual effects on tumor development. Current advances in the use of STING agonists as a novel strategy for antitumor therapy are also reviewed.

\section{Insights into the cGAS-STING signal transduction cascade}

cGAS is an innate immune sensor that identifies various cytosolic dsDNA, including DNA with viral, bacterial, mitochondrial, micronuclei, and retroelement origins, which can be mainly divided into pathogen-derived DNA and self-DNA (Table 1). In the cytoplasm, cGAS is activated by interacting with dsDNA in a sequenceindependent but length-dependent manner [32-34]. Structural and biochemical analyses have revealed that the C-terminal lobe of cGAS contains a conserved zinc- ion-binding module that mediates DNA binding and cGAS dimerization [35, 36]. DNA ligands promote cGAS activation primarily by inducing conformational changes around the catalytic site, and in the DNAbinding structures of cGAS, the GS-containing loop undergoes conformational change to maintain stability, which is a major mechanism of cGAS activation by DNA [37]. In addition to the primary DNA-binding site mentioned above, the secondary site located beside the primary site is a helix formed between strands $\beta 7-\beta 8$ and several surface-exposed loops [38]. The proximity of the two DNA-binding sites in cGAS leads to a 2:2 cGAS: DNA complex assembly, in which two cGAS molecules embrace two molecules of dsDNA [39, 40]. The cGAS dimers are organized in "head-to-head" alignment next to the DNA [41] and thus form stable "ladder-like" networks between one long curved dsDNA helix or two independent dsDNA strands [33, 42]. In this way, each individual cGAS-dsDNA complex can be cooperatively stabilized and can lead to stronger enzymatic activity, which may provide a possible explanation for longer dsDNA as more likely to activate cGAS [43]. In addition, long DNA is more efficient than short DNA in driving the liquid-liquid phase separation of cGAS, and the formation of cGAS liquid-like droplets is critically dependent on the concentration of cGAS and DNA in the cytoplasm [44]. cGAS and dsDNA are spatially concentrated in liquid droplets to facilitate cGAS dimerization and activation [45-47]. Once cGAS and

Table 1 Classification of the cytosolic dsDNA that activates the CGAS-STING signaling axis

\begin{tabular}{|c|c|c|c|c|}
\hline Classification & \multicolumn{2}{|c|}{ Source of dsDNA } & Possible mechanisms & References \\
\hline \multirow[t]{3}{*}{ Self-DNA } & \multicolumn{2}{|l|}{ Micronuclei } & $\begin{array}{l}\text { Rupture of the micronuclei membrane leads to exposure } \\
\text { of chromatin DNA that is recognized by CGAS, which } \\
\text { activates the CGAS-STING pathway. }\end{array}$ & {$[12]$} \\
\hline & \multicolumn{2}{|c|}{ Mitochondrion } & $\begin{array}{l}\text { Mitochondrial stress induces mtDNA leakage into the } \\
\text { cytosol, thus activating the STING pathway and inducing } \\
\text { production of cytokines. }\end{array}$ & [13] \\
\hline & \multicolumn{2}{|l|}{ Nuclear RNA } & $\begin{array}{l}\text { Facilitated by endogenous retroelements, nuclear RNA } \\
\text { can be reversely transcribed into DNA that activates } \\
\text { cGAS-STING signaling. }\end{array}$ & {$[10]$} \\
\hline \multirow[t]{4}{*}{$\begin{array}{l}\text { Pathogen- } \\
\text { derived DNA }\end{array}$} & DNA virus & $\begin{array}{l}\text { HSV1, HSV2, KSHV, adenovirus, vaccinia } \\
\text { virus, cytomegalovirus, papillomavirus, } \\
\text { murine gamma-herpesvirus } 68\end{array}$ & $\begin{array}{l}\text { DNA viruses invade host cells and release pathogen-derived } \\
\text { DNA to induce STING activation. }\end{array}$ & [14-20] \\
\hline & Retrovirus & HIV, SIV, murine leukemia virus & $\begin{array}{l}\text { DNA intermediates generated from reverse transcription may } \\
\text { be recognized by CGAS to stimulate downstream STING } \\
\text { signaling. }\end{array}$ & [11] \\
\hline & RNA virus & $\begin{array}{l}\text { West Nile virus, dengue virus, VSV, } \\
\text { SARS-COV-2 }\end{array}$ & $\begin{array}{l}\text { Infection with RNA viruses might cause cellular damage and } \\
\text { cell death, which results in the release of cellular DNA and } \\
\text { further activation of the CGAS-STING axis; SARS-CoV-2 binding } \\
\text { to ACE2 can lead to excessive angiotensin II signaling that } \\
\text { activates the STING pathway in mice. }\end{array}$ & {$[21-23]$} \\
\hline & Bacteria & $\begin{array}{l}\text { Listeria monocytogenes, Mycobacterium } \\
\text { tuberculosis, Listeria, Shigella, Francisella, } \\
\text { Chlamydia and Neisseria }\end{array}$ & $\begin{array}{l}\text { Bacteria produce CDNs, such as cyclic di-GMP and cyclic } \\
\text { di-AMP, which can directly bind to and activate STING. }\end{array}$ & $\begin{array}{l}{[10,24-} \\
31]\end{array}$ \\
\hline
\end{tabular}

$H S V 1$, herpes simplex virus 1; HSV2, herpes simplex virus 2; KSHV, Kaposi sarcoma-associated herpesvirus; HIV, human immunodeficiency virus; SIV, simian immunodeficiency virus; VSV, vesicular stomatitis virus; CDNs, cyclic dinucleotides; and SARS-COV-2, severe acute respiratory syndrome coronavirus 2 
dsDNA interacts, structural switches rearrange the catalytic pocket to enable cGAS to catalyze the synthesis of 2'3'-cyclic GMP-AMP (2'3'-cGAMP), with ATP and GTP as substrates. The first step in this process is the formation of a linear dinucleotide $5^{\prime}$-pppG $\left(2^{\prime}-5^{\prime}\right) \mathrm{pA}$ with ATP serving as the donor and $2^{\prime}-\mathrm{OH}$ on GTP serving as the acceptor. Then, the intermediate product flips over in the catalytic pocket, placing GTP at the donor position and AMP at the acceptor position to form a second $3^{\prime}-5^{\prime}$ phosphodiester bond [32, 35, 48]. Notably, although dsRNA or single-strand DNA (ssDNA) is able to bind to cGAS, neither can rearrange the catalytic pocket, which may explain the exclusive activation of cGAS by dsDNA. Ultimately, cGAMP acts as a second messenger to bind to and activate STING, a small endoplasmic reticulum (ER)-located protein $(\sim 40 \mathrm{KD})$ with four putative transmembrane domains [49, 50]. Normally, in a resting state, STING is retained in the ER by interacting with the $\mathrm{Ca}^{2+}$ sensor stromal interaction molecule 1 (STIM1) [51]. The cytosolic ligand-binding domain (LBD) of STING exists as the most functional unit capable of integrating with 2'3'- cGAMP or CDNs (cyclic dinucleotides) such as c-di-AMP, c-di-GMP or 3' 3'-cGAMP from bacteria. Upon interaction, the obvious closure of the ligand binding pocket in the LBD is observed, which is related to the activation of STING [52]. Next, STING transforms into a tetramer through a highorder oligomerization reaction and is translocated from the ER to the perinuclear area facilitated by cytoplasmic coat protein complex II (COPII) and ADP-ribosylation factor (ARF) GTPases [53, 54]. In the Golgi, STING is palmitoylated at two cysteine residues (Cys88 and Cys91), a posttranslational modification necessary for STING activation [55]. Modified STING recruits the kinase TANK-binding kinase 1 (TBK1); in turn, the Cterminal domains of STING are phosphorylated by TBK1; and then, phosphorylated STING recruits interferon regulatory factor 3 (IRF3), which is also phosphorylated by TBK1 and dimerizes; ultimately, dimerized IRF3 enters the nucleus and exerts its function in the transcription of type I IFNs and interferon-stimulated genes (ISGs) [56]. In parallel, STING can also bind to and stimulate IкB kinase (IKK) to mediate the production of nuclear factor- $\mathrm{kB}(\mathrm{NF}-\mathrm{kB})$-driven inflammatory genes. Upon signal transduction termination, STING is transferred to endolysosomes for degradation [14]. Considering that cGAMP can be transferred through gap junctions or delivered in viral/exosome packages, cGASSTING signaling may be activated in the cytoplasm without dsDNA [57, 58]. Moreover, newly produced type I IFNs activate heterodimer interferon receptors (IFNA R1 and IFNAR2) through paracrine signaling and thus induce the transcription of ISGs $[59,60]$. In summary, once virus-derived DNA and self-DNA are located in the cytoplasm, they can be sensed by cGAS, and a 2:2 cGAS:dsDNA complex is formed to catalyze the synthesis of 2'3'-cGAMP with ATP and GTP. Then, 2'3'cGAMP and bacteria-derived CDNs induce STING activation and mediate the release of downstream type I IFNs, TNF- $\alpha$ and IL- 6 , which are prerequisites for antimicrobial defense and antitumor effects. The whole process shows that the dsDNA-cGAS-STING axis can lead to the activation of both innate and adaptive immunity (Fig. 1).

\section{The antitumor functions of the CGAS-STING signaling pathway}

Recent evidence has revealed the close association of the cGAS-STING pathway with cancer development. This signaling pathway is generally regarded as a potent regulator of cancer immunity. A STING-mediated immune supportive microenvironment can hamper malignancy occurrence [61].

\section{Tumor cell cytosolic dsDNA induces STING activation} Under normal circumstances, DNA is strictly unaffiliated with the cytoplasm in eukaryotic cells to avoid autoimmunity [62]. However, DNA leaks aberrantly in tumor cells [63, 64]. Cancer cells share common features, including genome instability, tumor suppressor gene mutation or deletion, oxidative stress and vigorous metabolism [65]. Under these intense states, nuclear and mitochondrial DNA is fragile and easily damaged, which leads to eventual DNA leakage in the forms of micronuclei, chromatin fragments and/or free telomeric DNA [12, 66, 67]. Chromosomal instability (CIN) is the primary source of cytoplasmic DNA in malignant cells and is generally associated with tumor progression, distant metastasis and therapeutic tolerance [61]. Excessive proliferation of cancer cells results in unstable genomes [68, 69], usually characterized by chromosomal missegregation during mitosis. Due to defects in segregation, lagging chromosomes generate micronuclei in a cell cycle-dependent manner [12]. The vulnerable membrane of micronuclei easily exposes the inner DNA to the cytoplasm and activates the cGAS-STING signaling axis [12, 70]. Exogenous stimuli such as chemotherapy and irradiation can also cause DNA damage. In addition to leaked nuclear DNA, oxidative stress-induced mitochondrial DNA leakage is another crucial initiator of STING pathway activation. Several anticancer treatments that precisely attack mitochondrial membranes result in efflux and cell death. Therefore, the permeabilization of mitochondria membranes provides a reasonable explanation for mitochondrial DNA escape [71, 72]. Other sources, such as apoptotic cell-derived DNA, exosomal DNA (ExoDNA), and transposable elements, have also been 


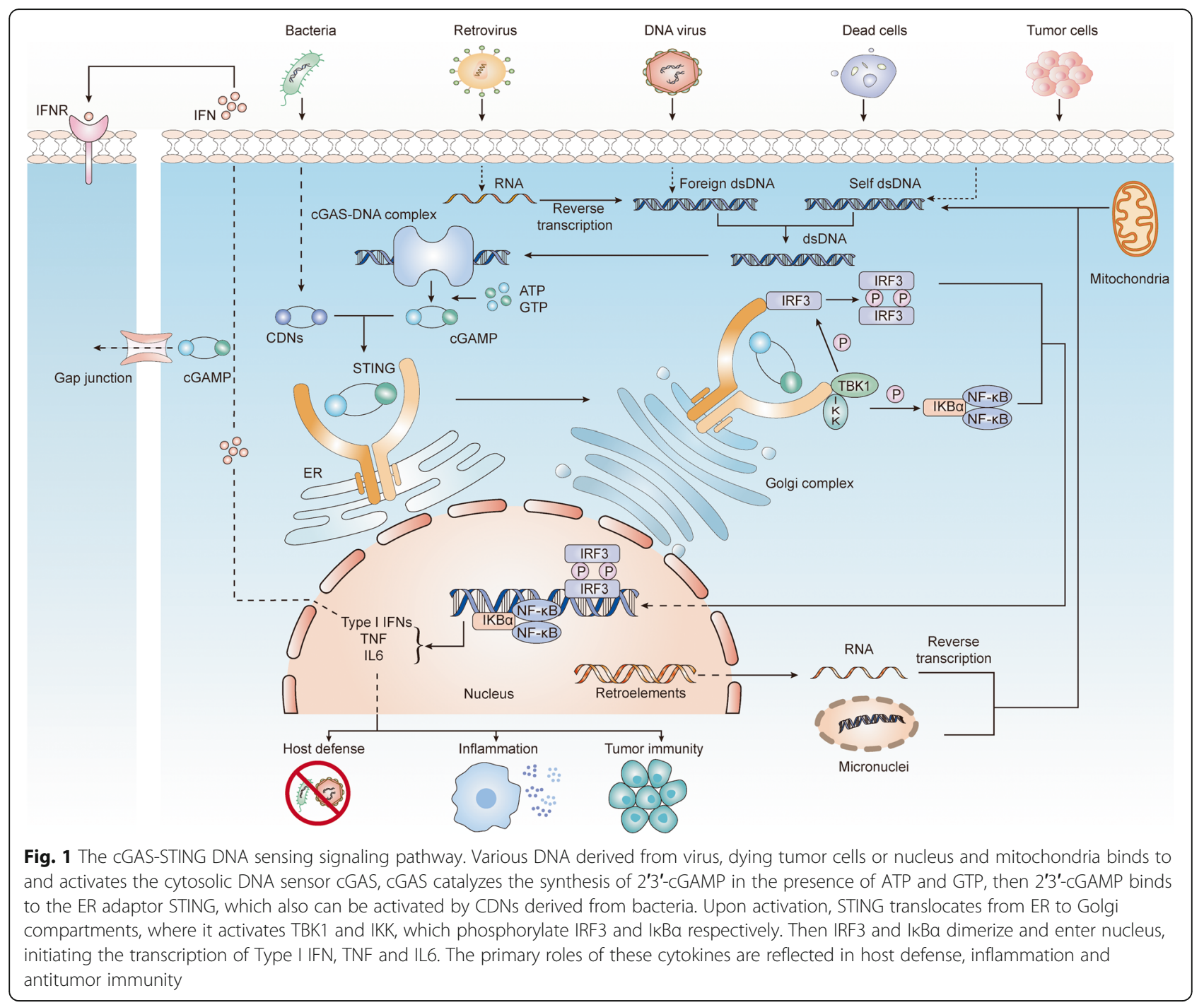

demonstrated to evoke cGAS-STING activation in tumor cells $[73,74]$.

\section{Type I IFNs: mediators of STING and adaptive antitumor effects}

cGAS-STING signaling exerts antitumor functions in cancer cells both in an autonomous and nonautonomous manner. On the one hand, DNA damage can provoke acute STING signal transduction and induce cellular senescence, an irreversible cell cycle arrest state, which thwarts the aberrant proliferation of tumor cells through acquisition of the senescence-associated secretory phenotype (SASP), which is associated with the release of abundant inflammatory mediators, proteases and growth factors [41, 75, 76]. In contrast to undergoing senescence, tumor cells also directly propel apoptosis processes by upregulating proapoptosis protein BCL2associated X (BAX) and downregulating the BCL2 apoptosis regulator [77]. On the other hand, STING activation in tumor cells not only facilitates the transcription of downstream type I IFNs to induce dendritic cell maturation but also recruits supportive immune cells for direct, nonspontaneous tumor elimination [78].

STING activation in nonmalignant cells causes tumor suppressive effects as well. STING signaling protects against colitis-associated carcinomas (CACs) induced by azoxymethane (AOM) and dextran sulfate sodium (DSS), which induce DNA damage in intestinal epithelial cells and further trigger STING activation. Downstream cytokines of STING signaling, such as IL-1 $\beta$ and IL-18, prevent neoplastic transformation by facilitating wound repair. More importantly, STING signaling can also provoke cytotoxic $\mathrm{T}$ cell responses to control tumorigenesis [66]. Necrotic cancer cells are commonly engulfed by antigen-presenting cells, especially the basic leucine zipper transcription factor ATF-like 3 (BATF3)-driven lineage of dendritic cells (DCs) [59]. BATF3 DCs take in tumor-associated antigens and migrate towards the 
tumor-draining lymph node via the lymphatic system, where they cross-prime tumor-specific $\mathrm{CD}^{+} \mathrm{T}$ cells. Then, $\mathrm{CD}^{+} \mathrm{T}$ cells undergo activation and clonal expansion in the lymph nodes and are trafficked through blood vessels to kill tumor cells. In turn, damaged cancer cells release more antigens that are further captured by DCs, the whole process forms a positive feedback loop called the cancer-immunity cycle [79]. Tumor eradication can be achieved by multiple processes in the cancer-immunity cycle, including tumor antigen capture and presentation and $\mathrm{T}$ cell priming and activation, with tumor antigen-specific $\mathrm{T}$ cell priming and activation relying on DCs and type I IFN release [80]. The involvement of type I IFNs in innate immune sensing and adaptive immunity provides a reasonable hypothesis for exploring candidate PRR pathways as potential immunomodulators. Mice lacking TLR9, myeloid differentiation primary response gene 88 (MyD88), cytosolic RNA sensor MAVS or the purinergic receptor P2X7R maintain intact antitumor immunity responses, whereas mice deficient in STING or IRF3 present with impaired CD8 ${ }^{+} \mathrm{T}$ cell priming and activation [81, 82]. In fact, dying tumor cells can release multiple damage-associated molecular patterns (DAMPs) to trigger innate immune responses in DCs; among these released stimuli, tumor cell-derived DNA is a pivotal inducer. In general, the phagocytosis of apoptotic cells causes immune silence because of DNase-based degradation [66]. Nevertheless, tumor cellreleased DNA can be preserved in the DC endolysosomal compartment through an unknown mechanism [66, 82]. cGAS recognizes DNA invading the cytoplasm and induces the activation of STING cascades, excretion of type I IFNs and expression of ISGs. Additionally, under some physiological conditions, such as hypoxia and acidic environments, nuclear or mitochondrial DNA might be packaged in exosomes. Exosomal DNA (ExoDNA) animates STING signaling once it is absorbed by tumor-infiltrating DCs [83]. Finally, tumor cellderived cGAMP can also be transferred to host DCs by the folate transporter SLC19A1 and then directly binds to STING, activating it in DCs [84]. A recent study more directly demonstrated that cell-autonomous STING promoted the maintenance of stem cell-like $\mathrm{CD} 8^{+} \mathrm{T}$ cells and augmented antitumor $\mathrm{T}$ cell responses, and mechanistically, cGAS-STING-mediated type I interferon signaling reinforced the stem cell-like $\mathrm{CD}^{+} \mathrm{T}$ cell differentiation program mainly by restraining Akt activity [85].

Immune cell-derived type I IFNs have crucial functions in antitumor immunity control. On the one hand, type I IFNs boost cross presentation by various mechanisms: first, they stimulate the maturation of DCs; second, they slow the endosome-lysosome acidification process to prevent engulfed tumor antigen clearance and elevate the expression of MHC I molecules on the cell surface [80, 86, 87]; finally, they accelerate DC migration towards lymph nodes, where they can cross-prime tumor-specific $\mathrm{CD}^{+} \mathrm{T}$ cells [88]. On the other hand, type I IFNs drive the expression of multiple chemokines, such as CXCL9 and CXCL10, both of which are necessary for cytotoxic $\mathrm{T}$ lymphocyte (CTL) transfer and infiltration [89]. Similarly, type I IFNs restrain the default immune suppressive action of regulatory $\mathrm{T}\left(\mathrm{T}_{\text {reg }}\right)$ cells by downregulating phosphodiesterase 4 (PDE4) and upregulating cyclic AMP (cAMP) [90]. Consequently, type I IFNs serve as bridges linking the cGAS-STING pathway with $\mathrm{CD}^{+} \mathrm{T}$ cell-mediated antitumor immunity. The antitumor mechanisms of the cGAS-STING signaling axis are illustrated in Fig. 2.

Indeed, previous studies revealed that STING activation can stimulate antitumor immune responses in leukemia, melanoma, glioma and hepatocellular carcinoma [91-94]. Additionally, STING expression is downregulated in a wide variety of tumor tissues and cell lines, according to a pan-cancer analysis, with a small proportion of tumors (approximately 1-25\%) bearing silent STING expression [95]. Lower STING expression was found in hepatic carcinoma and gastric cancer compared with its level in corresponding normal tissues, and this lower expression level was correlated with higher tumor stage and poorer prognosis $[96,97]$. Consistently, compared with that in the MCFG-10A mammary epithelial cell line, lower STING expression was detected in malignant breast cancer cell lines, including MCF-7, HBL100 and T47-D cells, as well as human melanoma cell lines and colorectal adenocarcinoma lines [96, 98, 99]. Collectively, these findings suggest that cGASSTING signaling might act as a tumor suppressor in certain types of cancers.

\section{STING pathway agonists as cancer therapeutics}

The immunostimulatory potential of the cGAS-STING pathway makes it an attractive pharmacological target, since its activation in the tumor microenvironment (TME) can induce efficient cross-priming of tumorspecific antigens and facilitate the infiltration of effector $\mathrm{T}$ cells. Recent drug research has focused on the development of STING agonists because of their potential in anticancer therapy $[100,101]$. To date, various kinds of STING agonists have been discovered, and they are mainly divided into the following categories: cyclic dinucleotides and their derivates, DMXAA and its analogs, and small molecular agonists. In addition, some conventional antitumor therapeutics can also indirectly activate STING, such as chemotherapy, radiotherapy (RT), and targeted therapy [102]. In addition, STING agonists are able to enhance the efficacy of other anticancer therapeutic agents when used in combination. STING 


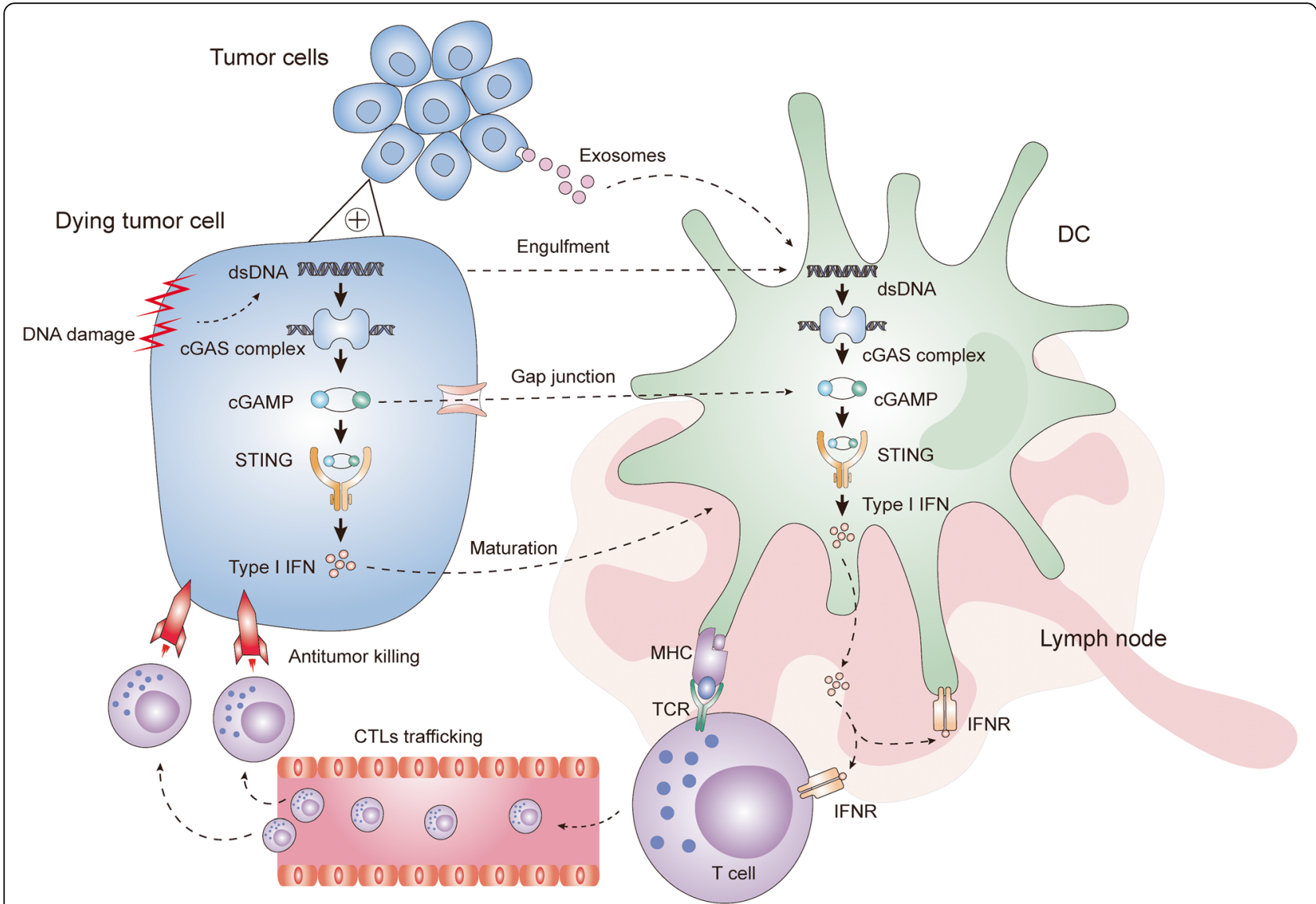

Fig. 2 The antitumor immunity effect of the CGAS-STING pathway. DNA damage leads to the formation of dsDNA in tumor cells, upon its stimulation, STING signaling is activated and promotes the release of Type I IFN, which is crucial for DC maturation. STING signaling activation in DCs is the core step of the whole cancer-immunity cycle, which can be initiated through engulfment of dying/damaged tumor cells, exosome transfer and CGAMP gap junctions. Then DCs migrate towards the tumor-draining lymph node and cross-prime tumor specific CD $8^{+} \mathrm{T}$ cells with the help of Type I IFNs. Finally, T cells undergo clonal expansion and traffic through the blood vessel to conduct tumor killing

agonists and their synergistic use with other remedies is further explored in detail below.

\section{Cyclic dinucleotides (CDNs)}

CDNs constitute a main type of STING agonist, which mainly originate from bacteria. The known natural CDNs consist of exogenous cyclic di-GMP (c-di-GMP), c-di-AMP, 3'3'-cGAMP and endogenous 2'3'-cGAMP. Among these, c-di-GMP, c-di-AMP, and 3'3'-cGAMP are synthesized by bacteria and identified as secondary messengers that mediate STING signal transduction in prokaryotic cells, while 2'3'-cGAMP functions as the initiator of STING in mammalian cells [103]. The antitumor potential of these natural dinucleotides was first proven by the finding that c-di-GMP could inhibit the proliferation of human colon cancer cells in vitro, and basal cell proliferation of human cecal adenocarcinoma (H508 cells) was inhibited with $50 \mu \mathrm{M}$ c-di-GMP [104]. Intraperitoneal (i.p.) injection of high-dose c-di-GMP directly activated caspase-3 and triggered 4T1 tumor cell apoptosis in vitro; $15 \mathrm{nmol}$ of c-di-GMP reduced the growth of 4 T1 tumor cells in vitro by $70 \%$ and $150 \mathrm{~nm}$ reduced it by $92 \%$, while low-dose c-di-GMP (0.01-2 $\mathrm{nmol}$ ) accelerated the adaptive $\mathrm{T}$ cell response by converting a subgroup of myeloid-derived suppressor cells (MDSCs) into immune stimulatory cells producing IL-12 [105]. Consistently, i.p. injection of 3'3'-cGAMP (10 $\mathrm{mg} / \mathrm{kg}$ ) expedited dramatic leukemic elimination in ElTCL1 transgenic mice bearing chronic lymphocytic leukemia (CLL) and promoted tumor shrinkage of multiple myeloma in vivo [106]. From the perspective of endogenous CDNs, 2' $3^{\prime}$-cGAMP (>5 mg/ $\mathrm{kg}$ ) was also shown to restrain tumorigenesis and improve the survival rate of mice bearing CT26 colon adenocarcinoma in a dosage-dependent manner, relying on DC activation and $\mathrm{T}$ cell cross-priming [107]. More recently, Ohkuri, T. et al. further demonstrated that intratumoral (i.t.) injection of $2^{\prime} 3^{\prime}$-cGAMP $(2.5 \mu \mathrm{g} / 25 \mu \mathrm{L} /$ dose $)$ on 5 and 10 days after the injection of tumor cells significantly mitigated tumor growth and prolonged the survival of breast 
cancer (4 T1-luc), squamous cell carcinoma (mSCC1), colon cancer (CT26), and melanoma (B16F10) mouse models [108]. Notably, the i.t. injection of $2{ }^{\prime} 3{ }^{\prime}$-cGAMP inhibited not only tumor growth but also lung metastases in mice bearing B16F10 cell-derived tumors, suggesting that cGAMP-induced $\mathrm{CD}^{+}{ }^{+} \mathrm{T}$-cell priming can drive systemic antitumor immunity to control local and distant tumor growth [109].

Considering the superior properties of STING signaling in activating adaptive immunity, it is rational to utilize STING agonists such as CDNs as cancer vaccine adjuvants to increase tumor immunogenicity [110]. Fu et al. investigated the in vivo therapeutic efficacy of a cancer vaccine termed STINGVAX, comprising granulocyte-macrophage colony-stimulating factor (GMCSF) and bacteria-derived or synthetic CDNs. They observed that after i.t. injection of STINGVAX (with 20$200 \mu \mathrm{g}$ of CDNs per vaccine dose), the volume of B16 melanoma tumors was dramatically reduced in a dosedependent manner. Compared to mice receiving GMCSF cancer vaccine alone, STINGVAX-treated mice had more infiltrating $\mathrm{CD}^{+} \mathrm{IFN}^{-} \gamma^{+} \mathrm{T}$ cells in the tumor microenvironment. The in vivo antitumor effect of STIN GVAX was also verified in models of colon carcinoma (CT26), pancreatic carcinoma (Panc02) and upper aerodigestive squamous cell carcinoma (SCCFVII) [111].

Although natural CDNs are able to produce robust antitumor immunity, their chemical features might hinder their future application in the clinical setting. First, native $\mathrm{CDNs}$ are easily degraded by enzymes inside the cell or in the bloodstream. Second, their negatively charged property, hydrophilicity and phosphate moieties severely impede CDNs from penetrating cell membranes to activate cytosolic STING, leading to low bioavailability and poor retention of the CDNs in specific cells and tissues. Third, unintentional toxicities and narrow therapeutic windows are also unavoidable. Thus, new strategies to improve therapeutic efficacy and reduce adverse effects are urgently needed, including drug delivery carrier engineering, original structural modification and nonnucleotide agonist screening [112]. Regarding agonist delivery, Smith et al. reported that biopolymer implants codelivering c-di-GMP $(6 \mu \mathrm{g})$ and chimeric antigen receptor $\mathrm{T}(\mathrm{CAR}-\mathrm{T})$ cells resulted in significant tumor regression in mice bearing pancreatic tumors [113]. Moreover, intravenous (i.v.) administration of c-diGMP/YSK05-Lip (equivalent to $3 \mu \mathrm{g}$ of c-di-GMP), a YSK05-liposome delivery system encapsulating c-diGMP, led to a tremendous decrease in metastatic lesions in a B16F10 mouse melanoma model, with nearly $40 \%$ of the injected mice showing resistance against tumor relapse, indicating that the adaptive immune response memory was successfully induced [114]. Chen et al. also found that intravenous (i.v.) injection of liposomal nanoparticle-delivered cGAMP (cGAMP-NP) could activate the STING axis more effectively than soluble cGAMP and converted the immunosuppressive TME to a tumoricidal state in a transplanted B16F10 cell melanoma model and in a genetically engineered triplenegative breast cancer model [115]. Moreover, a recent study creatively suggested that modified bacteria might be exploited as a selective carrier of STING agonists. Introduction of a di-nucleotide cyclase-coding gene into the Escherichia coli Nissle strain was an attempt at realizing this effect; however, advancements to the system are needed [102].

Apart from improving delivery methods, CDNs with superior properties are currently being synthesized and tested. For instance, to prevent enzymatic hydrolysis of cGAMP, the nonbridging oxygen atoms in cGAMP phosphodiester linkages were replaced by sulfur atoms. The modified compound, 2'3'cGsAsMP, showed resistance against degradation by ENPP1, a major 2'3'-cGAMP hydrolase, thereby leading to a longer half-life and sustained high affinity for human STING (hSTING) [116]. Synthetic dithio mixed-linkage CDNs with both $R p, R p(R, R)$ and $\mathrm{Rp}, \mathrm{Sp}(\mathrm{R}, \mathrm{S})$ dithio diastereomers possessed not only resistance to digestion by snake venom phosphodiesterase but also enhanced affinity for STING. A novel, superior modified product, ML RRS2 CDA (also termed ADU-S100), had the potency to activate all hSTING variants and mouse STING (mSTING). ADU-S100 had higher efficiency in activating STING signaling than endogenous or exogenous CDNs, mainly because of its enhanced stability and lipophilicity. Its powerful tumor elimination effect was extensively demonstrated in multiple murine models, including B16 melanoma, $4 \mathrm{~T}-1$ breast cancer and CT26 colon cancer, with all treated animals showing significant and durable tumor regression after i.t. injection of ADU-S100 (three $50 \mathrm{mg}$ doses) when tumor volumes reached $100 \mathrm{~mm}^{3}$ [117]. The remarkable curative effect and high affinity for hSTING laid the foundation for its clinical use. Related clinical trials of ADU-S100 are outlined in Table 3. In addition to ADU-S100, some other novel STING agonists have been well designed. IACS-8779 and IACS-8803 are two highly potent $2^{\prime} 3$ ' -thiophosphate $\mathrm{CDN}$ analogs that induced striking systemic antitumor responses in a B16 melanoma murine model after i.t. injection $(10 \mu \mathrm{g}$ on 6,9 and 12 days posttumor implantation) compared with ADU-S100 or cGAMP [118]. The characteristics and preclinical applications of all these mentioned CNDs are summarized in Table 2. Because of the structural modification and optimization of delivery strategies, the application range and efficacy of CDNs have been 
Table 2 Characteristics and preclinical applications of different STING agonists

\begin{tabular}{|c|c|c|c|c|c|c|}
\hline Classification & & Characteristics & $\begin{array}{l}\text { Application } \\
\text { models }\end{array}$ & $\begin{array}{l}\text { Treatment } \\
\text { information }\end{array}$ & Therapeutic effects & References \\
\hline \multirow[t]{12}{*}{$\begin{array}{l}\text { Natural CDN } \\
\text { agonists }\end{array}$} & \multirow[t]{4}{*}{ c-di-GMP } & \multirow{4}{*}{$\begin{array}{l}\text { Poor membrane permeability; } \\
\text { suitable for various codelivery } \\
\text { technologies }\end{array}$} & $\begin{array}{l}\text { Colon cancer (H508 } \\
\text { cells); }\end{array}$ & $50 \mu \mathrm{M}$ & $\begin{array}{l}\text { Inhibits } \\
\text { proliferation }\end{array}$ & {$[104,105]$} \\
\hline & & & \multirow[t]{3}{*}{$\begin{array}{l}4 \mathrm{~T} 1 \text { metastatic } \\
\text { breast cancer }\end{array}$} & $15 \mathrm{nmol}$ (i.p.) & $\begin{array}{l}70 \% \text { tumor } \\
\text { regression }\end{array}$ & \\
\hline & & & & $150 \mathrm{nmol}$ (i.p.) & $\begin{array}{l}92 \% \text { tumor } \\
\text { regression }\end{array}$ & \\
\hline & & & & 0.01-2 nmol (i.p.) & $\begin{array}{l}\text { Accelerates T-cell } \\
\text { response }\end{array}$ & \\
\hline & \multirow[t]{2}{*}{ 3'3'-cGAMP } & \multirow[t]{2}{*}{$\begin{array}{l}\text { Higher binding affinity for } \\
\text { mSTING than for hSTING }\end{array}$} & $\begin{array}{l}\text { Chronic lymphocytic } \\
\text { leukemia; }\end{array}$ & 10 mg/kg (i.p.) & $\begin{array}{l}\text { Leukemia } \\
\text { elimination }\end{array}$ & [106] \\
\hline & & & multiple myeloma & 10 mg/kg (i.p.) & $\begin{array}{l}\text { Suppresses } \\
\text { growth }\end{array}$ & \\
\hline & \multirow[t]{6}{*}{ 2'3'-cGAMP } & \multirow{6}{*}{$\begin{array}{l}\text { Higher affinity for hSTING than } \\
\text { its lineage isomers; binds to } \\
\text { various STING nucleotide } \\
\text { polymorphisms observed in } \\
\text { humans; easily degraded by } \\
\text { phosphodiesterase; } \\
\text { impermeable to the cell } \\
\text { membrane }\end{array}$} & $\begin{array}{l}\text { CT26 colon } \\
\text { adenocarcinoma; }\end{array}$ & $>5 \mathrm{mg} / \mathrm{kg}$ & $\begin{array}{l}\text { Restrains } \\
\text { tumorigenesis; }\end{array}$ & {$[107,108]$} \\
\hline & & & & & $\begin{array}{l}\text { Improves survival } \\
\text { rate }\end{array}$ & \\
\hline & & & $\begin{array}{l}\text { breast cancer ( } 4 \mathrm{~T} 1 \text { - } \\
\text { luc); }\end{array}$ & $2.5 \mu \mathrm{g} / 25 \mu \mathrm{L} /$ dose (i.t.) & $\begin{array}{l}\text { Delays tumor } \\
\text { growth }\end{array}$ & \\
\hline & & & $\begin{array}{l}\text { squamous cell } \\
\text { carcinomas } \\
\text { (mSCC1); }\end{array}$ & $2.5 \mu \mathrm{g} / 25 \mu \mathrm{L} /$ dose (i.t.) & $\begin{array}{l}\text { Delays tumor } \\
\text { growth }\end{array}$ & \\
\hline & & & colon cancer (CT26); & $2.5 \mu \mathrm{g} / 25 \mu \mathrm{L} /$ dose (i.t.) & $\begin{array}{l}\text { Delays tumor } \\
\text { growth }\end{array}$ & \\
\hline & & & melanoma (B16F10) & $2.5 \mu \mathrm{g} / 25 \mu \mathrm{L} /$ dose (i.t.) & $\begin{array}{l}\text { Delays tumor } \\
\text { growth }\end{array}$ & \\
\hline \multirow[t]{12}{*}{$\begin{array}{l}\text { Synthetic } \\
\text { CDN } \\
\text { agonists }\end{array}$} & \multirow[t]{2}{*}{ STINGVAX } & \multirow[t]{2}{*}{$\begin{array}{l}\text { Potent in vivo antitumor efficacy } \\
\text { in multiple therapeutic models } \\
\text { of established cancer }\end{array}$} & $\begin{array}{l}\text { B16 melanoma; } \\
\text { colon carcinoma } \\
\text { (CT26); }\end{array}$ & \multirow[t]{2}{*}{ 20-200 ug CDNs (i.t.) } & \multirow[t]{2}{*}{$\begin{array}{l}\text { Reduces tumor } \\
\text { volume }\end{array}$} & \multirow[t]{2}{*}[104]{} \\
\hline & & & $\begin{array}{l}\text { pancreatic } \\
\text { carcinoma (Panc02) }\end{array}$ & & & \\
\hline & \multirow[t]{2}{*}{ cGAMP-NPs } & \multirow{2}{*}{$\begin{array}{l}\text { Liposomal nanoparticles (NPs) } \\
\text { deliver cGAMP intracellularly } \\
\text { more effectively than realized } \\
\text { with soluble cGAMP }\end{array}$} & B16F10 melanoma; & \multirow[t]{2}{*}{ i.v. } & \multirow{2}{*}{$\begin{array}{l}\text { Creates a } \\
\text { tumoricidal state }\end{array}$} & \multirow[t]{2}{*}[108]{} \\
\hline & & & TNBC & & & \\
\hline & $\begin{array}{l}\text { Biopolymer scaffolds (c- } \\
\text { di-GMP and CAR T cells) }\end{array}$ & $\begin{array}{l}\text { Eradicates tumors more } \\
\text { effectively than systemic } \\
\text { delivery }\end{array}$ & Pancreatic cancer & $6 \mu \mathrm{g} c-\mathrm{di}-\mathrm{GMP}$ & Tumor regression & [106] \\
\hline & c-di-GMP/YSK05-Lip & $\begin{array}{l}\text { YSK05 is a lipid that can efficiently } \\
\text { deliver c-di-GMP to the cytosol; } \\
\text { possesses high fusogenic activity, } \\
\text { which enhances endosomal } \\
\text { escape }\end{array}$ & $\begin{array}{l}\text { B16F10 mouse } \\
\text { melanoma }\end{array}$ & $3 \mu \mathrm{g} c$-di-GMP (i.v.) & $\begin{array}{l}\text { Decreases } \\
\text { metastasis }\end{array}$ & {$[107]$} \\
\hline & $2^{\prime 2} 3^{\prime}-c G s A s M P$ & $\begin{array}{l}\text { More resistant to degradation by } \\
\text { ENPP1; ten-fold more potent at } \\
\text { inducing IFN secretion; potential } \\
\text { use as a cancer vaccine adjuvant }\end{array}$ & THP1 monocytes & & & [116] \\
\hline & \multirow[t]{3}{*}{ ADU-S100 } & \multirow{3}{*}{$\begin{array}{l}\text { Improves stability and lipophilicity; } \\
\text { higher affinity for hSTING than } \\
\text { natural CDN agonists; capable to } \\
\text { activate all hSTING variants and } \\
\text { mSTING }\end{array}$} & B16 melanoma; & three $50 \mathrm{mg}$ doses (i.t.) & $\begin{array}{l}\text { Durable tumor } \\
\text { regression }\end{array}$ & \multirow[t]{3}{*}[117]{} \\
\hline & & & 4T-1 breast cancer; & three $50 \mathrm{mg}$ doses (i.t.) & $\begin{array}{l}\text { Durable tumor } \\
\text { regression }\end{array}$ & \\
\hline & & & MC26 colon cancer & three $50 \mathrm{mg}$ doses (i.t.) & $\begin{array}{l}\text { Durable tumor } \\
\text { regression }\end{array}$ & \\
\hline & IACS-8779 & \multirow{2}{*}{$\begin{array}{l}\text { Stimulates a superior systemic } \\
\text { antitumor response than } \\
\text { ADU-S100 and cGAMP }\end{array}$} & \multirow[t]{2}{*}{ B16 melanoma } & \multirow{3}{*}{$\begin{array}{l}10 \mu \mathrm{g} \text { on day } 6,9 \text { and } 12 \\
\text { posttumor implantation }\end{array}$} & \multirow{2}{*}{$\begin{array}{l}\text { Antitumor } \\
\text { response }\end{array}$} & \multirow[t]{2}{*}[118]{} \\
\hline & IACS-8803 & & & & & \\
\hline \multirow[t]{2}{*}{$\begin{array}{l}\text { Non-CDN } \\
\text { agonists }\end{array}$} & FAA & $\begin{array}{l}\text { Causes hemorrhagic necrosis; } \\
\text { failed in a phase I clinical trial } \\
\text { due to species specificity }\end{array}$ & $\begin{array}{l}\text { Murine colon } \\
\text { tumors }\end{array}$ & & $\begin{array}{l}\text { Extensive tumor } \\
\text { rejection }\end{array}$ & {$[119,120]$} \\
\hline & DMXAA & First discovered as a vascular & Rat mammary & 300 mg/kg (i.p.) & High anticancer & {$[91,117$,} \\
\hline
\end{tabular}


Table 2 Characteristics and preclinical applications of different STING agonists (Continued)

\begin{tabular}{|c|c|c|c|c|c|c|}
\hline \multicolumn{2}{|c|}{ Classification } & \multirow{3}{*}{$\begin{array}{l}\text { Characteristics } \\
\text { disrupting agent; high affinity } \\
\text { for mSTING, with minimal } \\
\text { effect on hSTING }\end{array}$} & \multirow{2}{*}{$\begin{array}{l}\text { Application } \\
\text { models } \\
\text { carcinoma; }\end{array}$} & \multirow[t]{2}{*}{$\begin{array}{l}\text { Treatment } \\
\text { information }\end{array}$} & \multirow{2}{*}{$\begin{array}{l}\text { Therapeutic effects } \\
\text { potency }\end{array}$} & \multirow{2}{*}{$\frac{\text { References }}{121-123]}$} \\
\hline & & & & & & \\
\hline & & & B16 melanoma; & $500 \mu g$ (i.t.) & $\begin{array}{l}\text { Accelerates tumor } \\
\text { rejection }\end{array}$ & \\
\hline & & & NETs; & 22.5 mg/kg (i.p.) & $\begin{array}{l}\text { Inhibits tumor } \\
\text { growth }\end{array}$ & \\
\hline & & & $\begin{array}{l}\text { acute myeloid } \\
\text { leukemia; }\end{array}$ & $450 \mu \mathrm{g}$ (i.v.) & $\begin{array}{l}\text { Inhibits tumor } \\
\text { growth }\end{array}$ & \\
\hline & & & glioma GL261; & 25 mg/kg (i.p.) & $\begin{array}{l}\text { Inhibits tumor } \\
\text { growth }\end{array}$ & \\
\hline & & & lung cancer & 25 mg/kg (i.p.) & $\begin{array}{l}\text { Inhibits tumor } \\
\text { growth }\end{array}$ & \\
\hline & & & $\begin{array}{l}\text { adrenocortical } \\
\text { cancer }\end{array}$ & 22.5 mg/kg (i.p.) & $\begin{array}{l}\text { Inhibits tumor } \\
\text { growth }\end{array}$ & \\
\hline & a-Mangostin & $\begin{array}{l}\text { Higher affinity for hSTING than } \\
\text { for mSTING }\end{array}$ & THP1 cells & & & [124] \\
\hline & CMA & $\begin{array}{l}\text { Exclusive mSTING agonist; } \\
\text { inactive against human cells }\end{array}$ & $\begin{array}{l}\text { HEK } 293 \text { T cells; } \\
\text { mouse } \\
\text { macrophages }\end{array}$ & & Antiviral activity & [125] \\
\hline \multirow[t]{9}{*}{$\begin{array}{l}\text { Indirect } \\
\text { agonists }\end{array}$} & \multirow[t]{2}{*}{ Radiotherapy } & \multirow{2}{*}{$\begin{array}{l}\text { Causes the release of cytosolic } \\
\text { DNA fragments; low RT doses } \\
\text { decrease TREX1, thus activating } \\
\text { STING }\end{array}$} & MC38 colon cancer; & $20 \mathrm{~Gy}$ & $\begin{array}{l}\text { Adaptive immune } \\
\text { response; }\end{array}$ & [126] \\
\hline & & & $\begin{array}{l}\text { HT29 colorectal } \\
\text { tumor cells }\end{array}$ & 6 Gy & $\begin{array}{l}\text { induces type III } \\
\text { IFNs }\end{array}$ & [127] \\
\hline & Cisplatin & $\begin{array}{l}\text { Forms DNA adducts and inhibits } \\
\text { DNA repair }\end{array}$ & $\begin{array}{l}\text { Epithelial ovarian } \\
\text { cancer }\end{array}$ & $11.8 \mu \mathrm{M}$ & $\begin{array}{l}\text { Accumulates T } \\
\text { cells }\end{array}$ & {$[128]$} \\
\hline & \multirow[t]{2}{*}{ Teniposide } & \multirow{2}{*}{$\begin{array}{l}\text { Activates STING; increases MHC } \\
\text { expression on the tumor cell } \\
\text { surface }\end{array}$} & B16 melanoma; & & \multirow{2}{*}{$\begin{array}{l}\text { Activates DC and } \\
T \text { cells }\end{array}$} & \multirow[t]{2}{*}{ [129] } \\
\hline & & & $\begin{array}{l}\text { colon cancer (CT26, } \\
\text { MC38) }\end{array}$ & & & \\
\hline & \multirow[t]{3}{*}{ PARPi (Olaparib) } & \multirow{3}{*}{$\begin{array}{l}\text { Generates cytoplasmic chromatin } \\
\text { fragments with characteristics of } \\
\text { micronuclei }\end{array}$} & $\begin{array}{l}\text { ERCC1-deficient } \\
\text { NSCLC cells; }\end{array}$ & & $\begin{array}{l}\text { Inhibits } \\
\text { proliferation }\end{array}$ & [130] \\
\hline & & & $\begin{array}{l}\text { Brca1-deficient } \\
\text { ovarian cancer; }\end{array}$ & 50 mg/kg/day (i.p.) & $\begin{array}{l}\text { Strong T-cell } \\
\text { cytotoxicity }\end{array}$ & [126] \\
\hline & & & Brca1-deficient TNBC & 50 mg/kg/day (i.p.) & $\begin{array}{l}\text { Strong T-cell } \\
\text { cytotoxicity }\end{array}$ & [131] \\
\hline & CHK1i (Prexasertib) & $\begin{array}{l}\text { Accelerates DNA double-strand } \\
\text { breaks and STING activation }\end{array}$ & SCLC tumors & 10 mg/kg twice daily & $\begin{array}{l}\text { Enhances T-cell } \\
\text { recruitment }\end{array}$ & [132] \\
\hline \multirow[t]{5}{*}{$\begin{array}{l}\text { Small- } \\
\text { molecule } \\
\text { agonists }\end{array}$} & $\mathrm{C} 11$ & $\begin{array}{l}\text { Triggers IRF3/IFN-dependent } \\
\text { responses in a STING-dependent } \\
\text { manner }\end{array}$ & THF cells & & $\begin{array}{l}\text { Blocks replication } \\
\text { of alphavirus }\end{array}$ & [133] \\
\hline & BNBC & $\begin{array}{l}\text { Induces innate immunity against } \\
\text { various viruses and promotes the } \\
\text { activation of adaptive immune } \\
\text { responses }\end{array}$ & $\begin{array}{l}\text { Primary human } \\
\text { fibroblasts and } \\
\text { PBMCs }\end{array}$ & & Antiviral activity & [134] \\
\hline & DSDP & $\begin{array}{l}\text { Induces proinflammatory cytokines } \\
\text { in a STING-dependent manner }\end{array}$ & Human fibroblasts & & Antiviral activity & [135] \\
\hline & G10 & $\begin{array}{l}\text { Selectively induces STING-dependent } \\
\text { synthesis and secretion of bioactive } \\
\text { IFNs; no evidence of binding directly } \\
\text { to STING }\end{array}$ & Human fibroblasts & & Antiviral activity & [136] \\
\hline & ABZI & $\begin{array}{l}\text { Activates STING in "open" } \\
\text { conformation; sub-micromolar } \\
\text { levels induce STING activation } \\
\text { and IFN production }\end{array}$ & Colon tumors & 1.5 mg/kg (i.v.) & $\begin{array}{l}80 \% \text { of a treated } \\
\text { group remained } \\
\text { tumor free }\end{array}$ & {$[52]$} \\
\hline
\end{tabular}

FAA, flavone acetic acid; DMXAA, 5,6-dimethylxanthenone-4-acetic acid; CMA, 10-carboxymethyl-9-acridanone; PARPi, PARP inhibitor; CHK1i, CHK1 inhibitor; C11, N-(Methylcarbamoyl)-2-\{[5-(4-methylphenyl)-1,3,4-oxadiazol-2-yl]sulfanyl\}-2-phenylacetamide; $B N B C, 6$-bromo-N-(naphthalen-1-yl)-benzo [d ][1, 3] dioxole5-carboxamide; DSDP, dispiro diketopiperazine; G10, 4-(2-chloro-6-fluorobenzyl)-N-(furan-2-ylmethyl)-3-oxo-3,4-dihydro-2H-benzo [b]thiazine-6-carboxamide; $A B Z I$, amidobenzimidazole; TNBC: Triple-Negative Breast Cancer; PBMC: Peripheral blood mononuclear cell; i.t.: intratumoral injection; i.p.: intraperitoneal injection; i.v.: intravenous injection 
dramatically expanded, and new agonists with better properties are expected to emerge.

\section{DMXAA and its analogs}

Non-CDN STING agonists are also being researched. Flavone acetic acid (FAA), an antitumor agent, has recently been identified as a mSTING agonist, which may result in the extensive rejection of murine colon tumors through hemorrhagic necrosis [137]. However, it failed in a phase I clinical trial and showed no effect in rat tumor models [119], probably due to its species specificity. In an attempt to obtain structurally similar compounds that can also induce tumor hemorrhagic necrosis, the structure of FAA was modified, and several analogs were generated. The flavone-8-acetic acid derivative 5,6-dimethylxanthenone-4-acetic acid (DMXAA) has been the most systematically studied [138]. Intraperitoneal injection of DMXAA $(300 \mathrm{mg} / \mathrm{kg})$ elicited high anticancer potency against rat mammary carcinoma [139] and showed antitumor functions in multiple mouse models (Table 2). Seven days after tumors were inoculated, i.t. injection of $500 \mu \mathrm{g}$ DMXAA accelerated the tumor abrogation in STING-expressing mice bearing B16 melanoma tumors, while STING-null mice were less responsive [117]. The inhibitory effects of DMXAA on cancer growth were also confirmed in mouse models of gastroenteropancreatic neuroendocrine tumors (NETs) (i.p., $22.5 \mathrm{mg} / \mathrm{kg}$ ), adrenocortical cancer (i.p., $22.5 \mathrm{mg} / \mathrm{kg}$ ) [121], acute myeloid leukemia (i.v., $450 \mu \mathrm{g}$ ) [91], glioma (GL261) (i.p., $25 \mathrm{mg} / \mathrm{kg}$ ) [122] and lung cancer (344SQELuc) (i.p., $25 \mathrm{mg} / \mathrm{kg}$ ) [123]. Unfortunately, DMXAA failed in clinical trials since its interaction was restricted to mSTING [140]. Another similar derivative named 10carboxymethyl-9-acridanone (CMA) was also identified as an exclusive mSTING agonist [125]. Despite the clinical failures, these valuable works spurred efforts to design novel non-nucleotide analogs with higher affinity for hSTING. To this end, Gao et al. designed C7functionalized DMXAA derivatives but without significant success [141]. However, Quan et al. revealed that the DMXAA derivative $\alpha$-mangostin was more efficient in activating hSTING than in activating mSTING [124]. These findings suggest that the rational design of DMXAA analogs will inspire the emergence of novel antitumor therapies.

\section{Indirect STING agonists}

The antitumor immunity function of direct STING agonists has been widely explored, but most STING agonists have limited clinical application due to their poor druggability. Thus, developing new STING agonists that are effective, safe and easy to administer remains a challenge. Some classical anticancer treatments originally designed for other intended mechanisms, such as radiotherapy, chemotherapy, and targeted therapy, might activate the STING pathway (Table 2) [102]. Indeed, irradiated tumor cells released genome fragments into the cytoplasm directly or shuttled self-DNA encapsulated in exosomes to host immune cells to prime STING activation and adaptive immune responses [83, 142]. High doses of radiation (20-30 Gy) elevated the expression of three prime repair exonuclease 1 (TREX1), a DNA nuclease that mainly degrades cytoplasmic DNA, to clear cytoplasmic dsDNA, while low doses of radiation therapy prevented TREX1 activation, thus stimulating DNA fragment release to activate the STING pathway [143]. For example, radiotherapy (20 Gy) evoked innate immune sensing dominated by the STING pathway in a MC38 tumor murine model, further driving the adaptive immune response to radiation [126]. Exposure to gamma rays $(6 \mathrm{~Gy})$ directly induced type III IFNs mediated by the STING signaling axis in HT29 colorectal tumor cells [127]. Chemotherapies can induce DNA damage and inhibit DNA repair simultaneously; damaged DNA then activates the cGASSTING axis to potentiate DC-mediated antigen presentation and T-cell priming [129, 144]. Chronic cisplatin treatment $(11.8 \mu \mathrm{M})$ promoted intratumoral T-cell accumulation and advanced tumor immunogenicity through the cGAS-STING pathway in an epithelial ovarian cancer mouse model [128]. Teniposide treatment facilitated MHC expression on the tumor cell surface and activated DCs and $\mathrm{T}$ cells in a STING-dependent manner [129]. Additionally, targeted therapies also possess the capacity to augment STING-mediated immune responses. For example, PARP inhibitor (PARPi) olaparib treatment generated cytoplasmic chromatin fragments with characteristics of micronuclei to promote cGAS-STING activation and downstream CCL5 secretion in ERCC1-deficient non-small cell lung cancer cells [130]. In addition, olaparib (i.p., $50 \mathrm{mg} / \mathrm{kg}$ daily) also elicited strong $\mathrm{T}$ cell-mediated cytotoxicity in a Brca1-deficient ovarian cancer mouse model and a BRCA1- and TP53deficient genetically engineered mouse model (GEMM) of triple-negative breast cancer (TNBC) $[131,145]$. The efficacy of olaparib was abolished when TBK1 inhibitors were coadministered to mouse ovarian tumors, which verified that intact STING signaling was indispensable for PARPi efficacy [126]. Moreover, the CHK1 inhibitor (CHK1i) prexasertib $(10 \mathrm{mg} / \mathrm{kg}$ twice daily) also accelerated DNA doublestrand breaks and STING activation, subsequently enhancing $\mathrm{T}$-cell recruitment and effector cell function in small cell lung cancer (SCLC) mouse tumors [132]. Therefore, conventional cancer therapies can mediate immune responses by modulating STING activation, 
which may expand their clinical application and promote their future use in combination with other drugs.

Some novel small-molecule compounds were also found to be indirect STING agonists (Table 2). Bryan Gall et al. conducted a high-throughput screening assay and identified a compound named $\mathrm{N}$-(Methylcarbamoyl)-2-\{[5-(4-methylphenyl)-1,3,4-oxadiazol-2-yl]sulfanyl\}-2-phenylacetamide (referred to as C11), which triggered IFN-mediated antiviral immune responses in a STING-dependent manner in THF cells [133]. Moreover, 6-bromo-N-(naphthalen-1-yl)-benzo [d ][1, 3] dioxole-5-carboxamide (also referred to as $\mathrm{BNBC}$ ) was reported to initiate innate immunity against a broad spectrum of viruses and adaptive immune responses in primary human fibroblasts and peripheral-blood mononuclear cells (PBMCs) [134]. Another compound, dispiro diketopiperazine (DSDP) and 4-(2-chloro-6-fluorobenzyl)-N-(furan-2-ylmethyl)-3-oxo-3,4-dihydro-2Hben-

zo[b]thiazine-6-carboxamide (referred to as G10), facilitated the selective secretion of proinflammatory cytokines from human fibroblasts in a STING-dependent manner [136]. No sufficient evidence indicates that the aforementioned small-molecule agonists bind directly to STING [135]. A recent study revealed that i.v. injection of amidobenzimidazole (ABZI) $(1.5 \mathrm{mg} / \mathrm{kg})$ in immunocompetent mice with established syngeneic colon tumors was able to induce tumor regression, with nearly $80 \%$ of the treated group remaining tumor free at the end of the study, and this strong inhibition effect was reversed by $\mathrm{CD} 8^{+} \mathrm{T}$-cell depletion [52].

\section{Combinations with other therapeutics}

STING agonists are considered ideal sensitizers for immune checkpoint inhibitors. First, preexisting CTLs are prerequisites for effective immune checkpoint inhibitor (ICI) treatment. Most tumors are insensitive to ICIs due to a lack of T-cell infiltration, but these "cold tumors" can be transformed into "hot tumors" by STING agonist-mediated T-cell priming and infiltration. This process might be related to the expression of IFNstimulated genes such as CXCL9 and CXCL10 [146]. Therefore, interventions supporting T-cell infiltration are conducive to alleviate ICI resistance. Second, the STING signaling axis enhances the susceptibility of tumor cells to immune attack by natural killer (NK) cells and CTLs [147]. Third, STING pathway activation is accompanied by the upregulation of several immune inhibitory factors, including PD-L1, IDO, and FOXP3, resulting in immune suppression and failed spontaneous tumor elimination [148]. The combination of STING agonists with ICIs such as CTLA-4 and PD-1 blockers not only can neutralize the immunosuppressive effect of STING agonists but can also sensitize cells to ICIs.
Indeed, the synergistic combination of RR-CDG (i.t., every 3 days) with a PD-L1 blockade (i.p.,100 $\mu \mathrm{g}$ ) stimulated stronger antitumor responses than monotherapy in a head and neck squamous cell cancer (HNSCC) mouse model [149]. Intramuscular (i.m.) delivery of cGAMP (1$10 \mu \mathrm{g})$ into a B16 melanoma mouse model strongly enhanced the antitumor effect of the PD-L1 blockade (i.p., $200 \mu \mathrm{g})$ [150]. Furthermore, the coadministration of STINGVAX (subcutaneous injection of $20 \mu \mathrm{g}$ of CDN per vaccine dose) with a PD-1 blocker (i.p., $200 \mu$ g, twice a week) prompted the regression of poorly immunogenic tumors that were not responsive to anti-PD1 monotherapy [111]. Complete tumor regression and long-term antitumor memory were formed in mice bearing TC-1 tumors after they received a combination therapy consisting of a STING-activating nanovaccine and PD-1 blockade [151]. More surprisingly, a therapeutic regimen containing the STING agonist MK-1454 (i.t. injection weekly for 9 weeks and then every 3 weeks) and pembrolizumab (i.v., $200 \mathrm{mg}$ every 3 weeks) have entered clinical tests for solid tumors and lymphomas (Table 3). As previously mentioned, some conventional antitumor therapies can stimulate STING-mediated adaptive immunity and may sensitize these tumors to other drugs. Treatment with olaparib (i.p., $50 \mathrm{mg} / \mathrm{kg} /$ day) and anti-PD1 antibody (i.p., $250 \mu \mathrm{g} /$ mouse every 3 days) led to sustained tumor growth control and extended survival time for BRCA-deficient ovarian cancer models [145]. The combination of PARPi (BMN673) (oral gavage, $0.33 \mathrm{mg} /$ $\mathrm{kg} /$ day) and anti-PDL1 antibody (i.p., $200 \mu \mathrm{g} / \mathrm{mouse}$, every 3 days) significantly mitigated the tumor burden in colorectal and ovarian syngeneic and nude mouse models [152]. In addition to synergizing anti-PD1 therapy, intact STING signaling is also indispensable for the antitumor effects of the CTLA-4 checkpoint blockade, as evidenced by the finding that mice grafted with STINGdeficient B16 tumors showed almost no tumor elimination after receiving a combination treatment of irradiation and anti-CTLA-4 antibody. More obviously, in a prostate cancer murine model, a combination cocktail containing anti-CTLA-4 antibody (i.p., $100 \mu \mathrm{g} /$ mouse), anti-PD-1 antibody (i.p., $250 \mu \mathrm{g} /$ mouse), anti-4-1BB antibody (i.p., $200 \mu \mathrm{g} /$ mouse) with the STING agonist CDG (i.t., $25 \mu \mathrm{g} / \mathrm{mouse}$ ) caused unprecedented tumor regression in $75 \%$ of the mice, demonstrating a higher cure rate than ICI monotherapy [153]. CAR-T cell therapy was used in combination with cdGMP in a pancreatic tumor mouse model, with the results showing complete tumor elimination in approximately $40 \%$ of the treated mice [113].

Growing evidence also recommends STING agonists as adjuvants with common antitumor therapies such as chemotherapy, radiotherapy and targeted therapy. Combination therapy using cisplatin (i.p., $6 \mathrm{mg} / \mathrm{kg}$ ) and 
Table 3 Feasible combination therapies in human clinical trials

\begin{tabular}{|c|c|c|c|c|c|}
\hline Treatment regimens & Cancer type & Phase & Status & Locations & NCT \\
\hline ADU-S100 + Anti-PD antibody & Metastatic/Recurrent Head and Neck Cancer & $\|$ & Recruiting & $\begin{array}{l}\text { United } \\
\text { States }\end{array}$ & $\overline{\text { NCT03937141 }}$ \\
\hline ADU-S100 + Anti-PD antibody & $\begin{array}{l}\text { Advanced/Metastatic Solid Tumors or } \\
\text { Lymphomas }\end{array}$ & । & $\begin{array}{l}\text { Active, not } \\
\text { recruiting }\end{array}$ & $\begin{array}{l}\text { United } \\
\text { States }\end{array}$ & NCT02675439 \\
\hline MK-1454 + Pembrolizumab & Solid Tumors and Lymphoma & । & Recruiting & $\begin{array}{l}\text { United } \\
\text { States }\end{array}$ & NCT03010176 \\
\hline $\begin{array}{l}\text { DMXAA + Taxane-based } \\
\text { chemotherapies }\end{array}$ & Solid Tumor Malignancies & । & Terminated & $\begin{array}{l}\text { United } \\
\text { States }\end{array}$ & NCT01290380 \\
\hline DMXAA + Docetaxel & Advanced or Recurrent Solid Tumors & I & Completed & Japan & NCT01285453 \\
\hline DMXAA + Paclitaxel and Carboplatin & Non-Small Cell Lung Cancer & III & Terminated & $\begin{array}{l}\text { United } \\
\text { States }\end{array}$ & NCT00662597 \\
\hline DMXAA + Cetuximab & Refractory Solid Tumors & । & Withdrawn & $\begin{array}{l}\text { United } \\
\text { States }\end{array}$ & NCT01031212 \\
\hline DMXAA + Docetaxel & Urothelial Carcinoma & $\|$ & Withdrawn & $\begin{array}{l}\text { United } \\
\text { States }\end{array}$ & NCT01071928 \\
\hline DMXAA + Paclitaxel and Carboplatin & Non-Small Cell Lung Cancer & । & Completed & Japan & NCT00674102 \\
\hline
\end{tabular}

cGAMP (i.t., $2.5 \mu \mathrm{g}$ ) showed potent antitumor effects in a CXCR3-dependent manner in mouse squamous cell carcinoma models [154]. The combined administration of 5-fluorouracil (5-FU) (i.p., $10 \mathrm{mg} / \mathrm{kg} /$ day) with cGAMP (i.t., $5 \mathrm{mg} / \mathrm{kg} /$ day) in a CT26 colon cancer murine model ameliorated tumor progression and reduced the intestinal side effects of the 5-FU treatment [107]. Similarly, i.t. injection of 2 '3' -cGAMP $(10 \mu \mathrm{g})$ significantly synergized the antitumor effect of radiation (20 Gy) in a STING-dependent manner in the MC38 tumor models, compared with the effect of monotherapy [126]. Congruent results were also observed in Panc02 pancreatic adenocarcinoma when radiotherapy (10 Gy) was combined with the STING agonist RR-S2-CDG $(10 \mu \mathrm{g})$; this combination regimen generated the $\mathrm{T}$-cell immunity required for the control of local tumors and distant metastasis [155]. In terms of targeted therapies, combined treatment with cetuximab and STING agonists facilitated tumor recession in patients with HPV-positive $\left(\mathrm{HPV}^{+}\right)$head neck squamous cell carcinoma (HNSCC), which may depend on cetuximab-mediated NK cell activation and DC maturation [156]. Additionally, Pei et al. demonstrated that the STAT3 inhibitor HJC0152 (i.t., $30 \mu \mathrm{g})$ also enhanced the treatment effect of the STING agonist c-di-AM (PS)2 (i.t., $10 \mu \mathrm{g}$ ), leading to significant tumor rejection in a $4 \mathrm{~T} 1$ breast cancer model [157]. Details of all the aforementioned combination treatment regimens are available in Table 4.

Nonetheless, not all tumors are responsive to STING agonists, especially those with tolerogenic DNA and low tumor antigenicity [160]. For tumors lacking sufficient cGAS or STING, such as melanoma, colorectal and alternative lengthening of telomeres (ALT)-related cancer, targeting the cGAS-STING pathway for antitumor therapy may not be feasible, and oncolytic virus treatment might represent an alternative approach [161].

\section{The protumor role of the cGAS-STING pathway}

Emerging evidence reveals that the cGAS-STING signaling cascade may have dichotomous effects on tumor development [66]. Highly aggressive and unstable tumors can paradoxically coopt cGAS-STING signaling to stimulate carcinogenesis. Accordingly, STING agonists should be carefully used with the contextual consideration of specific tumor stage, genotype and CIN [61]. In general, STING signaling is involved in malignant transformation mainly by creating an immune suppressive tumor microenvironment and promoting tumor metastasis (Fig. 3).

\section{STING participates in immunosuppression}

With chronic activation of STING signaling, a potential immune suppressive landscape is generated [61, 162]. For example, 7,12-dimethylbenz(a) anthracene (DMBA) leads to skin tumorigenesis by inducing nuclear DNA leakage and STING activation. Bone marrow transplant experiments further revealed that STING expression in hematopoietic stem cells is vital for DMBA-induced skin tumorigenesis [163]. STING activation in human $\mathrm{HPV}^{+}$ tongue squamous cell carcinoma (TSCC) could facilitate the infiltration of regulatory $\mathrm{T}$ cells (Tregs), and enriched Tregs in turn released IL-10 to restrain the activity of antigen-specific $\mathrm{T}$ cells, ultimately promoting tumor progression [164]. In another study, exposure of MC38 mouse colon tumors to radiation led to the mobilization of myeloid-derived suppressor cells (MDSCs) in a STING-dependent manner. An analysis of TCGA data sets also revealed that STING expression is positively correlated with the infiltration of almost all 
Table 4 Feasible combination therapies applied to preclinical tumor models

\begin{tabular}{|c|c|c|c|c|}
\hline \multicolumn{2}{|l|}{ Treatment regimens } & \multirow{2}{*}{$\begin{array}{l}\text { Cancer type } \\
\text { HNSCC }\end{array}$} & \multirow{2}{*}{\begin{tabular}{l}
\multicolumn{1}{c}{ Therapeutic effects } \\
Stronger antitumor effects than \\
monotherapy
\end{tabular}} & \multirow{2}{*}{$\frac{\text { References }}{[149]}$} \\
\hline $\begin{array}{l}\text { Immunotherapy-STING } \\
\text { agonists combination }\end{array}$ & RR-CDG (i.t., every 3 d) + PD-L1 blockade (i.p., 100 mg) & & & \\
\hline & 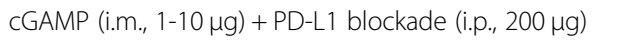 & B16 melanoma & Augments antitumor effect & [150] \\
\hline & $\begin{array}{l}\text { STINGVAX (subcutaneous injection } 20 \mu \mathrm{g} \text { CDN per } \\
\text { vaccine dose) + PD-1 blockade (i.p., } 200 \mu \mathrm{g} \text { twice a } \\
\text { week) }\end{array}$ & $\begin{array}{l}\text { CT26 colon } \\
\text { cancer }\end{array}$ & $\begin{array}{l}\text { Regression of poorly immunogenic } \\
\text { tumors }\end{array}$ & [111] \\
\hline & STING-activating nanovaccine + PD-1 blockade & $\begin{array}{l}\text { TC-1 tumor } \\
\text { models }\end{array}$ & Complete tumor regression & [151] \\
\hline & $\begin{array}{l}\text { PBAE-CDN (i.t., } 2 \mu \mathrm{g} \text { ) + anti-PD-1 antibody (i.p., } 100 \mu \mathrm{g} \\
\text { twice weekly) }\end{array}$ & $\begin{array}{l}\text { B16 melanoma } \\
\text { tumors }\end{array}$ & $\begin{array}{l}\text { Significantly reduces tumor growth } \\
\text { compared to unencapsulated CDNs }\end{array}$ & [158] \\
\hline & $\begin{array}{l}\text { Olaparib (i.p., } 50 \text { mg/kg/d) + anti-PD-L1 antibody (i.p., } \\
250 \text { mg every } 3 \text { days) }\end{array}$ & $\begin{array}{l}\text { BRCA-deficient } \\
\text { ovarian cancer }\end{array}$ & $\begin{array}{l}\text { Sustained tumor growth control and } \\
\text { extended survival }\end{array}$ & [126] \\
\hline & $\begin{array}{l}\text { BMN673 (oral gavage, } 0.33 \mathrm{mg} / \mathrm{kg} / \mathrm{d} \text { ) + anti-PD-L1 } \\
\text { antibody (i.p., } 200 \mu \mathrm{gg} \text {, every } 3 \text { days) }\end{array}$ & $\begin{array}{l}\text { Colorectal and } \\
\text { ovarian cancer }\end{array}$ & Reduces tumor burden & [152] \\
\hline & $\begin{array}{l}\text { Teniposide (i.p., } 10 \mathrm{mg} / \mathrm{kg} \text { ) + anti-PD1 antibody (i.p., } \\
100 \mu \mathrm{g} \text {, every } 3 \text { days) }\end{array}$ & $\begin{array}{l}\text { B16 melanoma; } \\
\text { colon cancer }\end{array}$ & $\begin{array}{l}\text { Potentiates efficacy of anti-PD1 } \\
\text { therapy }\end{array}$ & [129] \\
\hline & Irradiation + anti-CTLA-4 blockade & B16 melanoma & $\begin{array}{l}\text { Significant reduction in the growth of } \\
\text { abscopal tumors }\end{array}$ & [70] \\
\hline & ICI cocktail (i.p., $100 \mu \mathrm{g})+$ CDG (i.t., $25 \mu \mathrm{g}$ ) & Prostate cancer & Higher cure rate than monotherapy & [153] \\
\hline & cdGMP + CAR-T cells & $\begin{array}{l}\text { Pancreatic } \\
\text { tumors }\end{array}$ & $\begin{array}{l}\text { Approximately one-half of the treated } \\
\text { mice had complete tumor } \\
\text { elimination }\end{array}$ & [113] \\
\hline \multirow[t]{2}{*}{$\begin{array}{l}\text { Chemotherapy-STING } \\
\text { agonists combination }\end{array}$} & cGAMP (i.t., 2.5 g) + cisplatin (i.p., 6 mg/kg) & $\begin{array}{l}\text { Squamous cell } \\
\text { carcinoma }\end{array}$ & Antitumor effects & [154] \\
\hline & cGAMP (i.t., 5 mg/kg/d) + 5-FU (i.p., 10 mg/kg/d) & CT26 cancer & Ameliorates tumor progression & [107] \\
\hline \multirow{2}{*}{$\begin{array}{l}\text { Radiotherapy-STING } \\
\text { agonists combination }\end{array}$} & 2'3'-cGAMP (10 Mg) + radiotherapy (20 Gy) & MC38 tumors & Significant antitumor effect & [126] \\
\hline & RR-S2-CDG (10 g) + radiotherapy (10 Gy) & $\begin{array}{l}\text { Panc02 } \\
\text { pancreatic } \\
\text { adenocarcinoma }\end{array}$ & $\begin{array}{l}\text { Controls local tumors and distant } \\
\text { metastasis }\end{array}$ & [155] \\
\hline \multirow{3}{*}{$\begin{array}{l}\text { Targeted therapy- } \\
\text { STING agonists } \\
\text { combination }\end{array}$} & cGAMP + cetuximab & $\mathrm{HPV}^{+} \mathrm{HNSCC}$ & Tumor recession & [156] \\
\hline & c-diAM (PS)2 (i.t., $10 \mu \mathrm{g})+$ STAT3 inhibitor (i.t., 30 g) & $\begin{array}{l}\text { Mouse } 4 \mathrm{~T} 1 \\
\text { tumors }\end{array}$ & Significant tumor regression & [157] \\
\hline & STING agonist $(50 \mu \mathrm{g})+$ GITR antibody $(100 \mu \mathrm{g})$ & B-cell lymphoma & Synergistic antitumor effects & [159] \\
\hline
\end{tabular}

HNSCC, head and neck squamous cell cancers; STINGVAX, granulocyte-macrophage colony-stimulating factor (GM-CSF) with CDNs; PBAE-CDN, poly (beta-amino ester) cyclic dinucleotide; $D M X A A, 5,6$-dimethylxanthenone-4-acetic acid; i.t.: intratumoral injection; i.p.: intraperitoneal injection; i.m.: intramuscle injection

immune cells, including MDSCs and Tregs, in pancancer, especially in bladder urothelial carcinoma, breast cancer, liver hepatocellular carcinoma, prostate adenocarcinoma and thyroid carcinoma [165]. An immune suppressive TME is characterized by the upregulated expression of the immune checkpoint indoleamine 2,3dioxygenase (IDO), a symbol of tumor immune evasion. However, in STING-knockout mice, significantly decreased IDO levels and MDSCs were detected in the TME of a Lewis lung carcinoma (LLC) mouse model. Further, LLC growth promoted by intact STING would be alleviated when IDO expression was suppressed [160]. Hence, immune inhibitory cells and IDO in the TME are required for the STING signaling -involved tumorigenesis $[160,166]$. In these cases, STINGtriggered IDO expression must be detected before STING agonists are applied, and combining IDO inhibitors with STING agonists may counteract detrimental effects. In addition, STING activation also enhanced the expression of PD-L1 and CCR2 in multiple mouse tumors, including colon cancer, tongue squamous carcinoma, and head and neck squamous cell carcinoma [111, 167]. High expression of CCR2 in MDSCs led to the aggregation of tumor-promoting monocytes, which was prevented by the simultaneous use of CCR2 antagonists [168]. Surprisingly, in contrast to the findings described above, STING activation also promoted the death of the T-cells expressing it, possibly due to unresolved ER stress [169]. The accumulation of $\mathrm{T}$ cells was observed in the spleen and lymph nodes of STINGdeficient mice [170]. In another experiment, STING expression was abrogated in $\mathrm{T}$ cells in a mixed bone marrow chimera model, while a significant increase in Ki67+ CD8+ memory T cells was found under STING- 


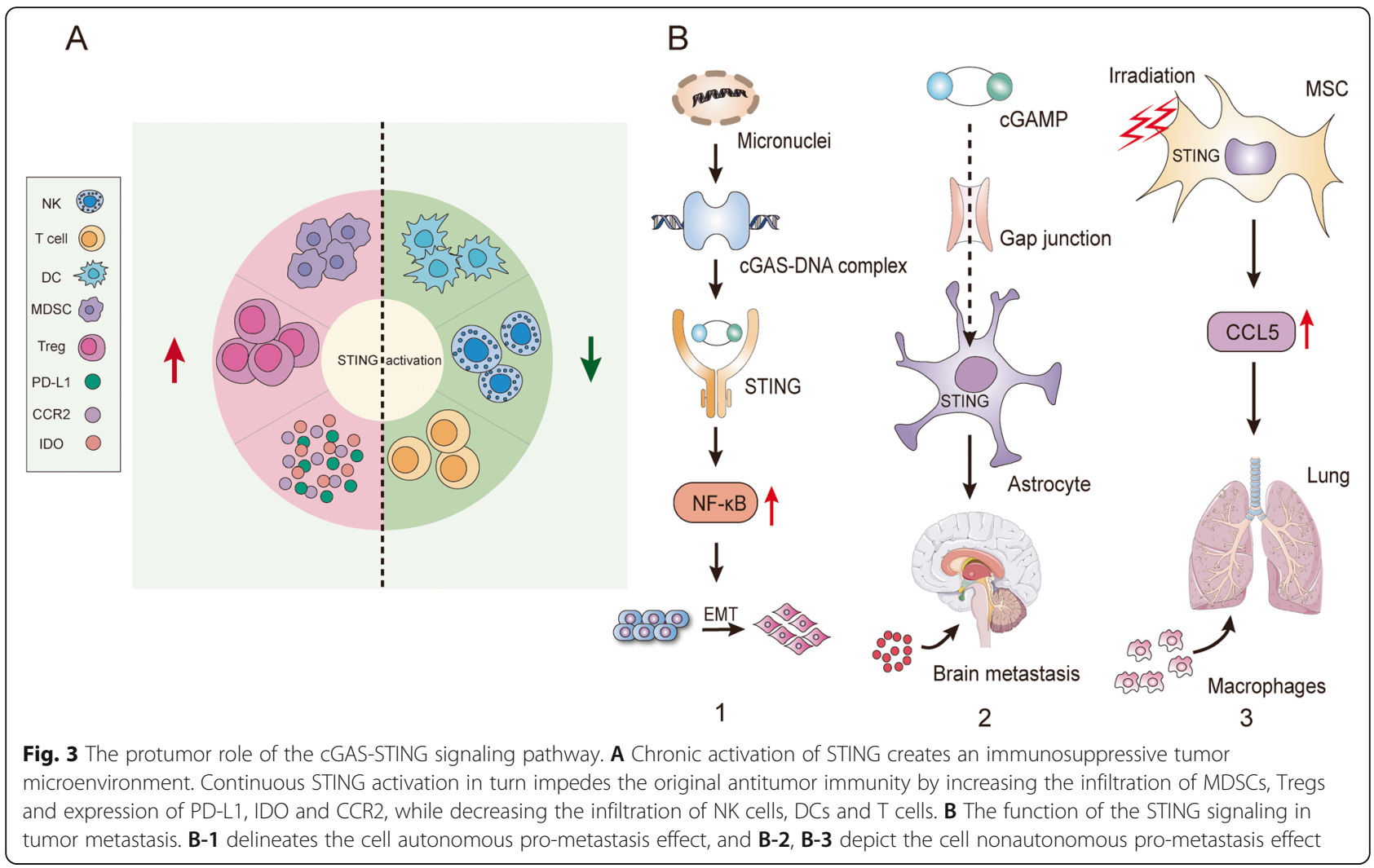

deficient conditions compared with the level in the untreated group [169, 170]. A series of studies suggested that STING activation in T cells may directly impair the adaptive immune system and accelerate tumorigenesis. Additional studies will be required to further delineate the explicit mechanism by which host STING activity facilitates a potent immune suppressive environment.

\section{An emerging characteristic of the STING pathway: prometastasis}

STING signaling is closely related to tumor metastasis in both a cell autonomous and nonautonomous manner [171]. On the one hand, chromosomal instability induced micronuclei formation and STING activation to trigger noncanonical NF- $\mathrm{kB}$ signaling and inflammatory responses, which favored the epithelial-to-mesenchymal transition and metastasis [171]. On the other hand, tumor cell metastasis may be driven by nonautonomous mechanisms. Intriguingly, facilitated by the connexin 43 protein (CX43) and protocadherin 7 (PCDH7), the cGAMP produced in tumor cells was exported to adjacent astrocytes via gap junctions [172]. In this way, STING was activated in astrocytes and subsequently initiated the release of inflammatory cytokines and the activation of STAT1 and NF- $\mathrm{kB}$, leading to brain metastasis of breast cancer and lung cancer [172]. Irradiated mesenchymal stromal cells (MSCs) also acquired the capacity to facilitate lung metastasis of breast cancer cells through cGAS-STING activation, and STINGmediated CCL5 expression increased the recruitment of macrophages for lung colonization [173].

Taken together, pieces of convincing evidence has revealed the dichotomous effects of the cGAS-STING pathway, although the complete mechanistic relevance of cGAS-STING signaling with respect to tumor development remains to be clarified. Therefore, we must extensively fine-tune the application range of STING agonists to avoid potential unintended adverse effects when used in the clinic.

\section{Concluding remarks}

In addition to the canonical role of cGAS-STING signaling in antimicrobial innate immunity, emerging evidence has proven that its activation also stimulates antitumor immune responses. These meaningful findings have spurred efforts to harness this natural defense-related pathway in the next generation of cancer immunotherapy. STING agonists have a remarkable ability to promote $\mathrm{CD}^{+} \mathrm{T}$ cell infiltration, which indicates that they can be utilized in combination with other therapeutic modalities for the effective treatment of cancer or other diseases. In vivo studies revealed that STING agonists can enhance the efficacy of multiple therapies, including but not limited to chemoradiotherapy, targeted therapy 
and immunotherapy, confirming that the modulation of the cGAS-STING signaling pathway may serve as a promising anticancer treatment. Notably, as a key inducer of type I IFN responses, the STING pathway that is chronically activated can instigate tumor growth and metastasis, an effect that is related to tumor stage, CIN state, and degree of STING activation. Hence, therapeutic windows and the tumor status must be carefully evaluated before the application of STING agonists in clinical practice. Moreover, another dilemma should be deliberated at this time: activation of STING can recruit both immune-supporting cells to inhibit malignant transformation and immunosuppressive cells to drive tumor progression. Unfortunately, which immune modulation will dominate in the context of different tumor types remains unknown. Further endeavors are warranted to reveal the underlying mechanisms of STING-mediated immune responses in specific tumors. Nevertheless, in-depth knowledge of the cGAS-STING signaling axis indeed represents exciting progress in the field of cancer immunology and clinical treatment of cancer.

\footnotetext{
Abbreviations

cGAS: Cyclic GMP-AMP synthase; STING: Stimulator of interferon genes; IFNs: Type I interferons; PRRs: Pattern-recognition receptors: PAMPs: Pathogen-associated molecular patterns; RIG-I : Retinoid acid inducible gene I; TLR9: Toll-like receptor 9; AIM2: AIM2-like receptor; 2'3'cGAMP: 2'3' -cyclic GMP-AMP; ssDNA: Single-chain DNA; ER: Endoplasmic reticulum; STIM1: Stromal interaction molecule 1; LBD: Ligand binding domain; COPII: Coat protein complex Il; ARF: ADP-ribosylation factor; TBK1: TANK-binding kinase 1; IRF3: Interferon regulatory factor 3; ISGs: Interferon-stimulated genes; IKK: IKB kinase; NF-KB: Nuclear factor-KB; HSV1: Herpes simplex virus 1; HSV2: Herpes simplex virus 2; KSHV: Kaposi sarcoma-associated herpesvirus; HIV: Human immunodeficiency virus: SIV: Simian immunodeficiency virus; VSV: Vesicular stomatitis virus; CDNs: Cyclic dinucleotides; SARS-COV-2: Severe acute respiratory syndrome coronavirus 2; CIN: Chromosomal instability; ExoDNA: Exosomal DNA; SASP: Senescence-associated secretory phenotype; BAX: BCL2-associated X; CAC: Colitis-associated carcinomas; AOM: Azoxymethane; DSS: Dextran sulfate sodium; DC: Dendritic cell; BATF3: Basic leucine zipper transcription factor ATF-like 3; DAMP: Damage-associated molecular pattern; CTL: Cytotoxic T lymphocyte; Treg: Regulatory T; PDE4: Phosphodiesterase 4; CAMP: Cyclic AMP; TME: Tumor microenvironment; MDSC: Myeloid-derived suppressor cells; CLL: Chronic lymphocytic leukemia; GM-CSF: Granulocytemacrophage colony-stimulating factor; CAR-T: Chimeric antigen receptor T; CGAMP-NP: Nanoparticle-delivered cGAMP; hSTING: Human STING; mSTING: Mouse STING; FAA: Flavone acetic acid;

NETs: Gastroenteropancreatic neuroendocrine tumors; CMA: 10carboxymethyl-9-acridanone; TREX1: Three prime repair exonuclease 1; PARPI: PARP inhibitor; GEMM: Genetically engineered mouse model; TNBC: Triple-negative breast cancer; SCLC: Small cell lung cancer; PBMC: Peripheral blood mononuclear cell; ABZI: Amidobenzimidazole; NK: Natural killer; 5-FU: 5-fluorouracil; HNSCC: Head neck squamous cell carcinoma; ALT: Alternative lengthening of telomeres; DMBA: 7,12dimethylbenz(a)anthracene; TSCC: Tongue squamous cell carcinoma; MDSC: Myeloid-derived suppressor cell; IDO: Indoleamine 2,3-dioxygenase; LLC: Lewis lung carcinoma; CX43: Connexin 43; PCDH7: Protocadherin 7; MSC: Mesenchymal stromal cell
}

\section{Acknowledgements}

None applicable.

\section{Authors' contributions}

LZQ and ZHH offered main direction and significant guidance for this manuscript. ZJY and MJL drafed the manuscript and illustrated the tables and figures for the manuscript. ZT, ZW, HS, YJY, YYN and ZW revised the manuscript. All authors approved the final manuscript.

\section{Funding}

This work was supported by the National Key Research and Development Program of China (2016YFC1306900), National Natural Science Foundation of China (81874327), Sanming Project of Medicine in Shenzhen

(SZSM201811057), Key Research and Development Program of Hunan Province (2019SK2251), and Innovation and Research Project of Development and Reform Committee of Hunan Province (2019-875).

\section{Availability of data and materials}

Not applicable.

Ethics approval and consent to participate

Not applicable.

\section{Consent for publication}

Not applicable.

\section{Competing interests}

The authors declare that they have no competing interests.

\section{Author details}

${ }^{1}$ Department of Clinical Pharmacology, Hunan Key Laboratory of Pharmacogenetics, and National Clinical Research Center for Geriatric Disorders, Xiangya Hospital, Central South University, Changsha 410008, People's Republic of China. ${ }^{2}$ Institute of Clinical Pharmacology, Engineering Research Center for applied Technology of Pharmacogenomics of Ministry of Education, Central South University, Changsha 410078, People's Republic of China. ${ }^{3}$ Shenzhen center for chronic disease control and Prevention, Shenzhen 518020, People's Republic of China. ${ }^{4}$ Hunan Yineng Biological Medicine Co., Ltd, Changsha 410205, People's Republic of China. ${ }^{5}$ Department of Nuclear Medicine, Key Laboratory of Biological Nanotechnology of National Health Commission, Xiangya Hospital, Central South University, Changsha, Hunan 410008, People's Republic of China.

Received: 17 June 2020 Accepted: 17 August 2020

Published online: 27 August 2020

\section{References}

1. Akira S, Uematsu S, Takeuchi O. Pathogen recognition and innate immunity. Cell. 2006;124:783-801

2. Tan X, Sun L, Chen J, Chen ZJ. Detection of microbial infections through innate immune sensing of nucleic acids. Annu Rev Microbiol. 2018;72:44778.

3. Mankan AK, Schmidt T, Chauhan D, Goldeck M, Honing K, Gaidt M, Kubarenko AV, Andreeva L, Hopfner KP, Hornung V. Cytosolic RNA:DNA hybrids activate the CGAS-STING axis. EMBO J. 2014;33:2937-46.

4. Takeuchi O, Akira S. Pattern recognition receptors and inflammation. Cell. 2010;140:805-20.

5. Hemmi H, Takeuchi O, Kawai T, Kaisho T, Sato S, Sanjo H, Matsumoto M, Hoshino K, Wagner H, Takeda K, Akira S. A toll-like receptor recognizes bacterial DNA. Nature. 2000;408:740-5.

6. Burckstummer T, Baumann C, Bluml S, Dixit E, Durnberger $G$, Jahn $H$, Planyavsky M, Bilban M, Colinge J, Bennett KL, Superti-Furga G. An orthogonal proteomic-genomic screen identifies AIM2 as a cytoplasmic DNA sensor for the inflammasome. Nat Immunol. 2009;10:266-72.

7. Fernandes-Alnemri T, Yu JW, Datta P, Wu J, Alnemri ES. AIM2 activates the inflammasome and cell death in response to cytoplasmic DNA. Nature. 2009:458:509-13.

8. Roberts TL, Idris A, Dunn JA, Kelly GM, Burnton CM, Hodgson S, Hardy LL, Garceau V, Sweet MJ, Ross IL, et al. HIN-200 proteins regulate caspase activation in response to foreign cytoplasmic DNA. Science. 2009;323:105760.

9. Feng $S$, Fox D, Man SM. Mechanisms of gasdermin family members in inflammasome signaling and cell death. J Mol Biol. 2018;430:3068-80. 
10. Chen $Q$, Sun L, Chen ZJ. Regulation and function of the CGAS-STING pathway of cytosolic DNA sensing. Nat Immunol. 2016;17:1142-9.

11. Barber GN. STING: infection, inflammation and cancer. Nat Rev Immunol. 2015;15:760-70

12. Mackenzie KJ, Carroll P, Martin CA, Murina O, Fluteau A, Simpson DJ, Olova $\mathrm{N}$, Sutcliffe $\mathrm{H}$, Rainger JK, Leitch $\mathrm{A}$, et al. cGAS surveillance of micronuclei links genome instability to innate immunity. Nature. 2017;548:461-5.

13. West AP, Khoury-Hanold W, Staron M, Tal MC, Pineda CM, Lang SM, Bestwick M, Duguay BA, Raimundo N, MacDuff DA, et al. Mitochondrial DNA stress primes the antiviral innate immune response. Nature. 2015;520:553-7.

14. Ma Z, Jacobs SR, West JA, Stopford C, Zhang Z, Davis Z, Barber GN, Glaunsinger BA, Dittmer DP, Damania B. Modulation of the CGAS-STING DNA sensing pathway by gammaherpesviruses. Proc Natl Acad Sci U S A. 2015;112:E4306-15.

15. Paijo J, Doring M, Spanier J, Grabski E, Nooruzzaman M, Schmidt T, Witte G, Messerle M, Hornung V, Kaever V, Kalinke U. cGAS senses human cytomegalovirus and induces type I interferon responses in human monocyte-derived cells. PLoS Pathog. 2016;12:e1005546.

16. Lio CW, McDonald B, Takahashi M, Dhanwani R, Sharma N, Huang J, Pham E, Benedict CA, Sharma S. CGAS-STING signaling regulates initial innate control of cytomegalovirus infection. J Virol. 2016;90:7789-97.

17. Zhang G, Chan B, Samarina N, Abere B, Weidner-Glunde M, Buch A, Pich A, Brinkmann MM, Schulz TF. Cytoplasmic isoforms of Kaposi sarcoma herpesvirus LANA recruit and antagonize the innate immune DNA sensor cGAS. Proc Natl Acad Sci U S A. 2016;113:E1034-43.

18. Wu JJ, Li W, Shao Y, Avey D, Fu B, Gillen J, Hand T, Ma S, Liu X, Miley W, et al. Inhibition of CGAS DNA sensing by a herpesvirus virion protein. Cell Host Microbe. 2015:18:333-44.

19. Li XD, Wu J, Gao D, Wang H, Sun L, Chen ZJ. Pivotal roles of CGAS-cGAMP signaling in antiviral defense and immune adjuvant effects. Science. 2013; 341:1390-4.

20. Schoggins JW, MacDuff DA, Imanaka N, Gainey MD, Shrestha B, Eitson JL, Mar KB, Richardson RB, Ratushny AV, Litvak V, et al. Pan-viral specificity of IFN-induced genes reveals new roles for CGAS in innate immunity. Nature. 2014;505:691-5.

21. Holm CK, Jensen SB, Jakobsen MR, Cheshenko N, Horan KA, Moeller HB, Gonzalez-Dosal R, Rasmussen SB, Christensen MH, Yarovinsky TO, et al. Virus-cell fusion as a trigger of innate immunity dependent on the adaptor STING. Nat Immunol. 2012;13:737-43.

22. Sun B, Sundstrom KB, Chew JJ, Bist P, Gan ES, Tan HC, Goh KC, Chawla T, Tang CK, Ooi EE. Dengue virus activates CGAS through the release of mitochondrial DNA. Sci Rep. 2017;7:3594.

23. Berthelot JM, Drouet L, Liote F. Kawasaki-like diseases and thrombotic coagulopathy in COVID-19: delayed over-activation of the STING pathway? Emerg Microbes Infect. 2020;9:1514-22.

24. Watson RO, Bell SL, MacDuff DA, Kimmey JM, Diner EJ, Olivas J, Vance RE, Stallings $\mathrm{CL}$, Virgin HW, Cox JS. The cytosolic sensor CGAS detects mycobacterium tuberculosis DNA to induce type I interferons and activate autophagy. Cell Host Microbe. 2015:17:811-9.

25. Wassermann R, Gulen MF, Sala C, Perin SG, Lou Y, Rybniker J, SchmidBurgk JL, Schmidt T, Hornung V, Cole ST, Ablasser A. Mycobacterium tuberculosis differentially activates CGAS- and inflammasome-dependent intracellular immune responses through ESX-1. Cell Host Microbe. 2015; 17:799-810

26. Collins AC, Cai H, Li T, Franco LH, Li XD, Nair VR, Scharn CR, Stamm CE, Levine B, Chen ZJ, Shiloh MU. Cyclic GMP-AMP synthase is an innate immune DNA sensor for mycobacterium tuberculosis. Cell Host Microbe. 2015;17:820-8.

27. Hansen K, Prabakaran T, Laustsen A, Jorgensen SE, Rahbaek SH, Jensen SB, Nielsen R, Leber JH, Decker T, Horan KA, et al. Listeria monocytogenes induces IFNbeta expression through an IFI16-, cGAS- and STING-dependent pathway. EMBO J. 2014;33:1654-66

28. Storek KM, Gertsvolf NA, Ohlson MB, Monack DM. cGAS and Ifi204 cooperate to produce type I IFNs in response to Francisella infection. J Immunol. 2015;194:3236-45.

29. Zhang Y, Yeruva L, Marinov A, Prantner D, Wyrick PB, Lupashin V, Nagarajan UM. The DNA sensor, cyclic GMP-AMP synthase, is essential for induction of IFN-beta during chlamydia trachomatis infection. J Immunol. 2014;193: 2394-404.

30. Andrade WA, Agarwal S, Mo S, Shaffer SA, Dillard JP, Schmidt T, Hornung V, Fitzgerald KA, Kurt-Jones EA, Golenbock DT. Type I interferon induction by
Neisseria gonorrhoeae: dual requirement of cyclic GMP-AMP synthase and toll-like receptor 4. Cell Rep. 2016;15:2438-48.

31. Andrade WA, Firon A, Schmidt T, Hornung V, Fitzgerald KA, Kurt-Jones EA, Trieu-Cuot P, Golenbock DT, Kaminski PA. Group B streptococcus degrades cyclic-di-AMP to modulate STING-dependent type I interferon production. Cell Host Microbe. 2016;20:49-59.

32. Sun L, Wu J, Du F, Chen X, Chen ZJ. Cyclic GMP-AMP synthase is a cytosolic DNA sensor that activates the type I interferon pathway. Science. 2013;339: 786-91.

33. Wu X, Wu FH, Wang X, Wang L, Siedow JN, Zhang W, Pei ZM. Molecular evolutionary and structural analysis of the cytosolic DNA sensor cGAS and STING. Nucleic Acids Res. 2014;42:8243-57.

34. Civril F, Deimling T, de Oliveira Mann CC, Ablasser A, Moldt M, Witte G, Hornung $V$, Hopfner KP. Structural mechanism of cytosolic DNA sensing by cGAS. Nature. 2013:498:332-7.

35. Zhang X, Bai XC, Chen ZJ. Structures and mechanisms in the CGAS-STING innate immunity pathway. Immunity. 2020;53:43-53.

36. Ouyang S, Song X, Wang Y, Ru H, Shaw N, Jiang Y, Niu F, Zhu Y, Qiu W, Parvatiyar K, et al. Structural analysis of the STING adaptor protein reveals a hydrophobic dimer interface and mode of cyclic di-GMP binding. Immunity. 2012:36:1073-86.

37. Donovan J, Dufner M, Korennykh A. Structural basis for cytosolic doublestranded RNA surveillance by human oligoadenylate synthetase 1. Proc Natl Acad Sci U S A. 2013;110:1652-7.

38. Li X, Shu C, Yi G, Chaton CT, Shelton CL, Diao J, Zuo X, Kao CC, Herr AB, Li P. Cyclic GMP-AMP synthase is activated by double-stranded DNA-induced oligomerization. Immunity. 2013;39:1019-31.

39. Kranzusch PJ, Lee ASY, Wilson SC, Solovykh MS, Vance RE, Berger JM, Doudna JA. Structure-guided reprogramming of human CGAS dinucleotide linkage specificity. Cell. 2014;158:1011-21.

40. Martin M, Hiroyasu A, Guzman RM, Roberts SA, Goodman AG. Analysis of drosophila STING reveals an evolutionarily conserved antimicrobial function. Cell Rep. 2018;23:3537-3550 e3536

41. Saeed A, Ruan X, Guan H, Su J, Ouyang S. Regulation of cGAS-mediated immune responses and immunotherapy. Adv Sci (Weinh). 2020;7:1902599.

42. Davies BW, Bogard RW, Young TS, Mekalanos JJ. Coordinated regulation of accessory genetic elements produces cyclic di-nucleotides for $\mathrm{V}$ cholerae virulence. Cell. 2012;149:358-70.

43. Zhang X, Wu J, Du F, Xu H, Sun L, Chen Z, Brautigam CA, Zhang X, Chen ZJ. The cytosolic DNA sensor cGAS forms an oligomeric complex with DNA and undergoes switch-like conformational changes in the activation loop. Cell Rep. 2014;6:421-30.

44. Gao D, Li T, Li XD, Chen X, Li QZ, Wight-Carter M, Chen ZJ. Activation of cyclic GMP-AMP synthase by self-DNA causes autoimmune diseases. Proc Natl Acad Sci U S A. 2015:112:E5699-705.

45. Andreeva L, Hiller B, Kostrewa D, Lassig C, de Oliveira Mann CC, Jan Drexler

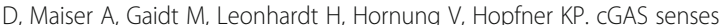
long and HMGB/TFAM-bound U-turn DNA by forming protein-DNA ladders. Nature. 2017:549:394-8.

46. Du M, Chen ZJ. DNA-induced liquid phase condensation of cGAS activates innate immune signaling. Science. 2018;361:704-9.

47. Zhou W, Whiteley AT, de Oliveira Mann CC, Morehouse BR, Nowak RP, Fischer ES, Gray NS, Mekalanos JJ, Kranzusch PJ. Structure of the human cGAS-DNA complex reveals enhanced control of immune surveillance. Cell. 2018:174:300-311 e311.

48. Wu J, Sun L, Chen X, Du F, Shi H, Chen C, Chen ZJ. Cyclic GMP-AMP is an endogenous second messenger in innate immune signaling by cytosolic DNA. Science. 2013;339:826-30.

49. Ng KW, Marshall EA, Bell JC, Lam WL. CGAS-STING and cancer: dichotomous roles in tumor immunity and development. Trends Immunol. 2018;39:44-54.

50. Motwani M, Pesiridis S, Fitzgerald KA. DNA sensing by the CGAS-STING pathway in health and disease. Nat Rev Genet. 2019;20:657-74.

51. Srikanth S, Woo JS, Wu B, El-Sherbiny YM, Leung J, Chupradit K, Rice L, Seo GJ, Calmettes G, Ramakrishna C, et al. The Ca $(2+)$ sensor STIM1 regulates the type I interferon response by retaining the signaling adaptor STING at the endoplasmic reticulum. Nat Immunol. 2019;20:152-62.

52. Ramanjulu JM, Pesiridis GS, Yang J, Concha N, Singhaus R, Zhang SY, Tran JL, Moore P, Lehmann S, Eberl HC, et al. Design of amidobenzimidazole STING receptor agonists with systemic activity. Nature. 2018;564:439-43. 
53. Dobbs N, Burnaevskiy N, Chen D, Gonugunta VK, Alto NM, Yan N. STING activation by translocation from the ER is associated with infection and autoinflammatory disease. Cell Host Microbe. 2015;18:157-68.

54. Shang G, Zhang C, Chen ZJ, Bai XC, Zhang X. Cryo-EM structures of STING reveal its mechanism of activation by cyclic GMP-AMP. Nature. 2019;567: 389-93.

55. Mukai K, Konno H, Akiba T, Uemura T, Waguri S, Kobayashi T, Barber GN, Arai $\mathrm{H}$, Taguchi T. Activation of STING requires palmitoylation at the Golgi. Nat Commun. 2016;7:11932.

56. Tao J, Zhou X, Jiang Z. cGAS-cGAMP-STING: the three musketeers of cytosolic DNA sensing and signaling. IUBMB Life. 2016;68:858-70.

57. Ablasser A, Schmid-Burgk JL, Hemmerling I, Horvath GL, Schmidt T, Latz E, Hornung V. Cell intrinsic immunity spreads to bystander cells via the intercellular transfer of cGAMP. Nature. 2013;503:530-4.

58. Gentili M, Kowal J, Tkach M, Satoh T, Lahaye X, Conrad C, Boyron M, Lombard B, Durand S, Kroemer G, et al. Transmission of innate immune signaling by packaging of cGAMP in viral particles. Science. 2015;349: 1232-6

59. Corrales L, Matson V, Flood B, Spranger S, Gajewski TF. Innate immune signaling and regulation in cancer immunotherapy. Cell Res. 2017;27:96108.

60. Zhu Y, An X, Zhang X, Qiao Y, Zheng T, Li X. STING: a master regulator in the cancer-immunity cycle. Mol Cancer. 2019;18:152.

61. Kwon J, Bakhoum SF. The cytosolic DNA-sensing CGAS-STING pathway in cancer. Cancer Discov. 2020;10:26-39.

62. Roers A, Hiller B, Hornung V. Recognition of endogenous nucleic acids by the innate immune system. Immunity. 2016;44:739-54.

63. Ho SS, Zhang WY, Tan NY, Khatoo M, Suter MA, Tripathi S, Cheung FS, Lim WK, Tan PH, Ngeow J, Gasser S. The DNA structure-specific endonuclease MUS81 mediates DNA sensor STING-dependent host rejection of prostate cancer cells. Immunity. 2016;44:1177-89.

64. Shen YJ, Le Bert N, Chitre AA, Koo CX, Nga XH, Ho SS, Khatoo M, Tan NY, Ishii KJ, Gasser S. Genome-derived cytosolic DNA mediates type I interferondependent rejection of B cell lymphoma cells. Cell Rep. 2015:11:460-73.

65. Luo J, Solimini NL, Elledge SJ. Principles of cancer therapy: oncogene and non-oncogene addiction. Cell. 2009;136:823-37.

66. Woo SR, Fuertes MB, Corrales L, Spranger S, Furdyna MJ, Leung MY, Duggan $R$, Wang Y, Barber GN, Fitzgerald KA, et al. STING-dependent cytosolic DNA sensing mediates innate immune recognition of immunogenic tumors. Immunity. 2014:41:830-42.

67. Chen YA, Shen YL, Hsia HY, Tiang YP, Sung TL, Chen LY. Extrachromosomal telomere repeat DNA is linked to ALT development via cGAS-STING DNA sensing pathway. Nat Struct Mol Biol. 2017;24:1124-31.

68. Parkes EE, Walker SM, Taggart LE, McCabe N, Knight LA, Wilkinson R, McCloskey KD, Buckley NE, Savage Kl, Salto-Tellez M, et al. Activation of STING-dependent innate immune signaling by S-phase-specific DNA damage in breast cancer. J Natl Cancer Inst. 2017;109:djw199.

69. Crasta K, Ganem NJ, Dagher R, Lantermann AB, Ivanova EV, Pan Y, Nezi L, Protopopov A, Chowdhury D, Pellman D. DNA breaks and chromosome pulverization from errors in mitosis. Nature. 2012;482:53-8.

70. Harding SM, Benci JL, Irianto J, Discher DE, Minn AJ, Greenberg RA. Mitotic progression following DNA damage enables pattern recognition within micronuclei. Nature. 2017:548:466-70.

71. Riley JS, Quarato G, Cloix C, Lopez J, O'Prey J, Pearson M, Chapman J, Sesaki $\mathrm{H}$, Carlin LM, Passos JF, et al. Mitochondrial inner membrane permeabilisation enables mtDNA release during apoptosis. EMBO J. 2018;37: e99238.

72. Fulda S, Galluzzi L, Kroemer G. Targeting mitochondria for cancer therapy. Nat Rev Drug Discov. 2010;9:447-64.

73. Boelens MC, Wu TJ, Nabet BY, Xu B, Qiu Y, Yoon T, Azzam DJ, Twyman-Saint Victor C, Wiemann BZ, Ishwaran $\mathrm{H}$, et al. Exosome transfer from stromal to breast cancer cells regulates therapy resistance pathways. Cell. 2014;159: 499-513.

74. Zomer A, Maynard C, Verweij FJ, Kamermans A, Schafer R, Beerling E, Schiffelers RM, de Wit E, Berenguer J, Ellenbroek SIJ, et al. In vivo imaging reveals extracellular vesicle-mediated phenocopying of metastatic behavior. Cell. 2015;161:1046-57.

75. Gluck S, Guey B, Gulen MF, Wolter K, Kang TW, Schmacke NA, Bridgeman A Rehwinkel J, Zender L, Ablasser A. Innate immune sensing of cytosolic chromatin fragments through CGAS promotes senescence. Nat Cell Biol. 2017:19:1061-70.
76. Coppe JP, Patil CK, Rodier F, Sun Y, Munoz DP, Goldstein J, Nelson PS, Desprez PY, Campisi J. Senescence-associated secretory phenotypes reveal cell-nonautonomous functions of oncogenic RAS and the p53 tumor suppressor. PLoS Biol. 2008:6:2853-68.

77. Vanpouille-Box C, Demaria S, Formenti SC, Galluzzi L. Cytosolic DNA sensing in organismal tumor control. Cancer Cell. 2018;34:361-78.

78. Ranoa DRE, Widau RC, Mallon S, Parekh AD, Nicolae CM, Huang X, Bolt MJ, Arina A, Parry R, Kron SJ, et al. STING promotes homeostasis via regulation of cell proliferation and chromosomal stability. Cancer Res. 2019;79:1465-79.

79. Chen DS, Mellman I. Oncology meets immunology: the cancer-immunity cycle. Immunity. 2013;39:1-10.

80. Diamond MS, Kinder M, Matsushita H, Mashayekhi M, Dunn GP Archambault JM, Lee H, Arthur CD, White JM, Kalinke U, et al. Type I interferon is selectively required by dendritic cells for immune rejection of tumors. J Exp Med. 2011;208:1989-2003.

81. Lister MF, Sharkey J, Sawatzky DA, Hodgkiss JP, Davidson DJ, Rossi AG, Finlayson $\mathrm{K}$. The role of the purinergic P2X7 receptor in inflammation. J Inflamm (Lond). 2007:4:5.

82. Klarquist J, Hennies CM, Lehn MA, Reboulet RA, Feau S, Janssen EM. STINGmediated DNA sensing promotes antitumor and autoimmune responses to dying cells. J Immunol. 2014;193:6124-34.

83. Diamond JM, Vanpouille-Box C, Spada S, Rudqvist NP, Chapman JR, Ueberheide BM, Pilones KA, Sarfraz Y, Formenti SC, Demaria S. Exosomes shuttle TREX1-sensitive IFN-stimulatory dsDNA from irradiated cancer cells to DCs. Cancer Immunol Res. 2018;6:910-20.

84. Ritchie C, Cordova AF, Hess GT, Bassik MC, Li L. SLC19A1 is an importer of the Immunotransmitter cGAMP. Mol Cell. 2019;75:372-381 e375.

85. Li W, Lu L, Lu J, Wang X, Yang C, Jin J, Wu L, Hong X, Li F, Cao D, et al. CGAS-STING-mediated DNA sensing maintains CD8(+) T cell stemness and promotes antitumor T cell therapy. Sci Transl Med. 2020;12:eaay9013.

86. Reboulet RA, Hennies CM, Garcia Z, Nierkens S, Janssen EM. Prolonged antigen storage endows merocytic dendritic cells with enhanced capacity to prime anti-tumor responses in tumor-bearing mice. J Immunol. 2010;185: 3337-47.

87. Lorenzi S, Mattei F, Sistigu A, Bracci L, Spadaro F, Sanchez M, Spada M Belardelli F, Gabriele L, Schiavoni G. Type I IFNs control antigen retention and survival of CD8alpha(+) dendritic cells after uptake of tumor apoptotic cells leading to cross-priming. J Immunol. 2011;186:5142-50.

88. Papewalis C, Jacobs B, Wuttke M, Ullrich E, Baehring T, Fenk $R$, Willenberg HS, Schinner S, Cohnen M, Seissler J, et al. IFN-alpha skews monocytes into CD56+-expressing dendritic cells with potent functional activities in vitro and in vivo. J Immunol. 2008;180:1462-70.

89. Padovan E, Spagnoli GC, Ferrantini M, Heberer M. IFN-alpha2a induces IP10/CXCL10 and MIG/CXCL9 production in monocyte-derived dendritic cells and enhances their capacity to attract and stimulate CD8+ effector T cells. J Leukoc Biol. 2002:71:669-76.

90. Bacher N, Raker V, Hofmann C, Graulich E, Schwenk M, Baumgrass R, Bopp T, Zechner U, Merten L, Becker C, Steinbrink K. Interferon-alpha suppresses CAMP to disarm human regulatory T cells. Cancer Res. 2013; 73:5647-56.

91. Curran E, Chen X, Corrales L, Kline DE, Dubensky TW Jr, Duttagupta P, Kortylewski M, Kline J. STING pathway activation stimulates potent immunity against acute myeloid leukemia. Cell Rep. 2016;15:2357-66.

92. Thomsen MK, Skouboe MK, Boularan C, Vernejoul F, Lioux T, Leknes SL, Berthelsen MF, Riedel M, Cai H, Joseph JV, et al. The cGAS-STING pathway is a therapeutic target in a preclinical model of hepatocellular carcinoma. Oncogene. 2020;39:1652-64.

93. Falahat R, Perez-Villarroel P, Mailloux AW, Zhu G, Pilon-Thomas S, Barber GN, Mule JJ. STING signaling in melanoma cells shapes antigenicity and can promote antitumor T-cell activity. Cancer Immunol Res. 2019;7:1837-48.

94. Ohkuri T, Ghosh A, Kosaka A, Zhu J, Ikeura M, David M, Watkins SC, Sarkar SN, Okada H. STING contributes to antiglioma immunity via triggering type I IFN signals in the tumor microenvironment. Cancer Immunol Res. 2014;2: 1199-208.

95. Konno H, Yamauchi S, Berglund A, Putney RM, Mule JJ, Barber GN. Suppression of STING signaling through epigenetic silencing and missense mutation impedes DNA damage mediated cytokine production. Oncogene. 2018;37:2037-51.

96. Xia T, Konno H, Barber GN. Recurrent loss of STING signaling in melanoma correlates with susceptibility to viral oncolysis. Cancer Res. 2016;76:6747-59. 
97. Song S, Peng P, Tang Z, Zhao J, Wu W, Li H, Shao M, Li L, Yang C, Duan F, et al. Decreased expression of STING predicts poor prognosis in patients with gastric cancer. Sci Rep. 2017;7:39858.

98. Bhatelia K, Singh A, Tomar D, Singh K, Sripada L, Chagtoo M, Prajapati P, Singh R, Godbole MM, Singh R. Antiviral signaling protein MITA acts as a tumor suppressor in breast cancer by regulating NF-kappaB induced cell death. Biochim Biophys Acta. 1842;2014:144-53.

99. Xia T, Konno H, Ahn J, Barber GN. Deregulation of STING signaling in colorectal carcinoma constrains DNA damage responses and correlates with tumorigenesis. Cell Rep. 2016;14:282-97.

100. Ablasser A, Chen ZJ. cGAS in action: expanding roles in immunity and inflammation. Science. 2019;363:eaat8657.

101. Corrales L, Gajewski TF. Molecular pathways: targeting the stimulator of interferon genes (STING) in the immunotherapy of cancer. Clin Cancer Res. 2015;21:4774-9.

102. Flood BA, Higgs EF, Li S, Luke JJ, Gajewski TF. STING pathway agonism as a cancer therapeutic. Immunol Rev. 2019;290:24-38.

103. Danilchanka O, Mekalanos JJ. Cyclic dinucleotides and the innate immune response. Cell. 2013;154:962-70.

104. Karaolis DK, Cheng K, Lipsky M, Elnabawi A, Catalano J, Hyodo M, Hayakawa Y, Raufman JP. 3',5'-cyclic diguanylic acid (c-di-GMP) inhibits basal and growth factor-stimulated human colon cancer cell proliferation. Biochem Biophys Res Commun. 2005;329:40-5.

105. Chandra D, Quispe-Tintaya W, Jahangir A, Asafu-Adjei D, Ramos I, Sintim HO, Zhou J, Hayakawa Y, Karaolis DK, Gravekamp C. STING ligand c-di-GMP improves cancer vaccination against metastatic breast cancer. Cancer Immunol Res. 2014:2:901-10.

106. Tang CH, Zundell JA, Ranatunga S, Lin C, Nefedova Y, Del Valle JR, Hu CC. Agonist-mediated activation of STING induces apoptosis in malignant B cells. Cancer Res. 2016;76:2137-52.

107. Li T, Cheng H, Yuan H, Xu Q, Shu C, Zhang Y, Xu P, Tan J, Rui Y, Li P, Tan X. Antitumor activity of CGAMP via stimulation of CGAS-CGAMP-STING-IRF3 mediated innate immune response. Sci Rep. 2016;6:19049.

108. Ohkuri T, Kosaka A, Ishibashi K, Kumai T, Hirata Y, Ohara K, Nagato T, Oikawa K, Aoki N, Harabuchi Y, et al. Intratumoral administration of CGAMP transiently accumulates potent macrophages for anti-tumor immunity at a mouse tumor site. Cancer Immunol Immunother. 2017;66:705-16.

109. Demaria O, De Gassart A, Coso S, Gestermann N, Di Domizio J, Flatz L, Gaide O, Michielin O, Hwu P, Petrova TV, et al. STING activation of tumor endothelial cells initiates spontaneous and therapeutic antitumor immunity. Proc Natl Acad Sci U S A. 2015;112:15408-13.

110. Ishikawa H, Ma Z, Barber GN. STING regulates intracellular DNA-mediated, type I interferon-dependent innate immunity. Nature. 2009;461:788-92.

111. Fu J, Kanne DB, Leong M, Glickman LH, McWhirter SM, Lemmens E, Mechette K, Leong JJ, Lauer P, Liu W, et al. STING agonist formulated cancer vaccines can cure established tumors resistant to PD-1 blockade. Sci Transl Med. 2015;7:283ra252.

112. Berger G, Marloye M, Lawler SE. Pharmacological modulation of the STING pathway for cancer immunotherapy. Trends Mol Med. 2019;25:412-27.

113. Smith TT, Moffett HF, Stephan SB, Opel CF, Dumigan AG, Jiang X, Pillarisetty VG, Pillai SPS, Wittrup KD, Stephan MT. Biopolymers codelivering engineered T cells and STING agonists can eliminate heterogeneous tumors. J Clin Invest. 2017;127:2176-91

114. Nakamura T, Miyabe H, Hyodo M, Sato Y, Hayakawa Y, Harashima H. Liposomes loaded with a STING pathway ligand, cyclic di-GMP, enhance cancer immunotherapy against metastatic melanoma. J Control Release. 2015;216:149-57.

115. Cheng N, Watkins-Schulz R, Junkins RD, David CN, Johnson BM, Montgomery SA, Peine KJ, Darr DB, Yuan H, McKinnon KP, et al. A nanoparticle-incorporated STING activator enhances antitumor immunity in PD-L1-insensitive models of triple-negative breast cancer. JCI Insight. 2018;3: e120638.

116. Li L, Yin Q, Kuss P, Maliga Z, Millan JL, Wu H, Mitchison TJ. Hydrolysis of 2'3'cGAMP by ENPP1 and design of nonhydrolyzable analogs. Nat Chem Biol. 2014;10:1043-8.

117. Corrales L, Glickman LH, McWhirter SM, Kanne DB, Sivick KE, Katibah GE, Woo SR, Lemmens E, Banda T, Leong JJ, et al. Direct activation of STING in the tumor microenvironment leads to potent and systemic tumor regression and immunity. Cell Rep. 2015;11:1018-30.

118. Ager $C R$, Zhang $H$, Wei Z, Jones $P$, Curran MA, Di Francesco ME. Discovery of IACS-8803 and IACS-8779, potent agonists of stimulator of interferon genes (STING) with robust systemic antitumor efficacy. Bioorg Med Chem Lett. 2019;29:126640.

119. Kroemer G, Galluzzi L, Kepp O, Zitvogel L. Immunogenic cell death in cancer therapy. Annu Rev Immunol. 2013;31:51-72.

120. Cummings J, Smyth JF. Flavone 8-acetic acid: our current understanding of its mechanism of action in solid tumours. Cancer Chemother Pharmacol. 1989;24:269-72.

121. Hantel C, Ozimek A, Lira R, Ragazzon B, Jackel C, Frantsev R, Reincke M, Bertherat J, Mussack T, Beuschlein F. TNF alpha signaling is associated with therapeutic responsiveness to vascular disrupting agents in endocrine tumors. Mol Cell Endocrinol. 2016;423:87-95.

122. Yung R, Seyfoddin V, Guise C, Tijono S, McGregor A, Connor B, Ching LM. Efficacy against subcutaneous or intracranial murine GL261 gliomas in relation to the concentration of the vascular-disrupting agent, 5,6dimethylxanthenone-4-acetic acid (DMXAA), in the brain and plasma. Cancer Chemother Pharmacol. 2014;73:639-49.

123. Downey CM, Aghaei M, Schwendener RA, Jirik FR. DMXAA causes tumor site-specific vascular disruption in murine non-small cell lung cancer, and like the endogenous non-canonical cyclic dinucleotide STING agonist, 2'3'CGAMP, induces M2 macrophage repolarization. PLoS One. 2014;9:e99988.

124. Zhang Y, Sun Z, Pei J, Luo Q, Zeng X, Li Q, Yang Z, Quan J. Identification of alpha-mangostin as an agonist of human STING. ChemMedChem. 2018;13: 2057-64.

125. Cavlar T, Deimling T, Ablasser A, Hopfner KP, Hornung V. Species-specific detection of the antiviral small-molecule compound CMA by STING. EMBO J. 2013;32:1440-50.

126. Deng $L$, Liang $H$, Xu M, Yang $X$, Burnette $B$, Arina A, Li XD, Mauceri $H$, Beckett M, Darga T, et al. STING-dependent cytosolic DNA sensing promotes radiation-induced type I interferon-dependent antitumor immunity in immunogenic tumors. Immunity. 2014;41:843-52.

127. Chen J, Markelc B, Kaeppler J, Ogundipe VML, Cao Y, McKenna WG, Muschel RJ. STING-dependent interferon-lambda1 induction in HT29 cells, a human colorectal cancer cell line, after gamma-radiation. Int J Radiat Oncol Biol Phys. 2018;101:97-106.

128. Grabosch S, Bulatovic M, Zeng F, Ma T, Zhang L, Ross M, Brozick J, Fang Y, Tseng G, Kim E, et al. Cisplatin-induced immune modulation in ovarian cancer mouse models with distinct inflammation profiles. Oncogene. 2019; 38:2380-93.

129. Wang Z, Chen J, Hu J, Zhang H, Xu F, He W, Wang X, Li M, Lu W, Zeng G, et al. CGAS/STING axis mediates a topoisomerase II inhibitor-induced tumor immunogenicity. J Clin Invest. 2019;129:4850-62.

130. Chabanon RM, Muirhead G, Krastev DB, Adam J, Morel D, Garrido M, Lamb A, Henon C, Dorvault N, Rouanne M, et al. PARP inhibition enhances tumor cell-intrinsic immunity in ERCC1-deficient non-small cell lung cancer. J Clin Invest. 2019:129:1211-28

131. Pantelidou C, Sonzogni O, De Oliveria TM, Mehta AK, Kothari A, Wang D, Visal T, Li MK, Pinto J, Castrillon JA, et al. PARP inhibitor efficacy depends on CD8(+) T-cell recruitment via intratumoral STING pathway activation in BRCA-deficient models of triple-negative breast cancer. Cancer Discov. 2019; 9:722-37.

132. Sen T, Rodriguez BL, Chen L, Corte CMD, Morikawa N, Fujimoto J, Cristea S, Nguyen T, Diao L, Li L, et al. Targeting DNA damage response promotes antitumor immunity through STING-mediated T-cell activation in small cell lung cancer. Cancer Discov. 2019;9:646-61.

133. Gall B, Pryke K, Abraham J, Mizuno N, Botto S, Sali TM, Broeckel R, Haese N, Nilsen A, Placzek A, et al. Emerging alphaviruses are sensitive to cellular states induced by a novel small-molecule agonist of the STING pathway. J Virol. 2018;92:e01913.

134. Zhang X, Liu B, Tang L, Su Q, Hwang N, Sehgal M, Cheng J, Ma J, Zhang X, Tan $Y$, et al. Discovery and mechanistic study of a novel human-stimulatorof-interferon-genes agonist. ACS Infect Dis. 2019;5:1139-49.

135. Liu B, Tang L, Zhang X, Ma J, Sehgal M, Cheng J, Zhang X, Zhou Y, Du Y, Kulp J, et al. A cell-based high throughput screening assay for the discovery of CGAS-STING pathway agonists. Antivir Res. 2017;147:37-46.

136. Sali TM, Pryke KM, Abraham J, Liu A, Archer I, Broeckel R, Staverosky JA, Smith JL, Al-Shammari A, Amsler $L$, et al. Characterization of a novel humanspecific STING agonist that elicits antiviral activity against emerging alphaviruses. PLoS Pathog. 2015;11:e1005324.

137. Plowman J, Narayanan VL, Dykes D, Szarvasi E, Briet P, Yoder OC, Paull KD. Flavone acetic acid: a novel agent with preclinical antitumor activity against colon adenocarcinoma 38 in mice. Cancer Treat Rep. 1986;70:631-5. 
138. Bibby MC, Phillips RM, Double JA, Pratesi G. Anti-tumour activity of flavone acetic acid (NSC 347512) in mice--influence of immune status. Br J Cancer. 1991;63:57-62.

139. Liu JJ, Ching LM, Goldthorpe M, Sutherland R, Baguley BC, Kirker JA, McKeage MJ. Antitumour action of 5,6-dimethylxanthenone-4-acetic acid in rats bearing chemically induced primary mammary tumours. Cancer Chemother Pharmacol. 2007;59:661-9.

140. Conlon J, Burdette DL, Sharma S, Bhat N, Thompson M, Jiang Z, Rathinam VA, Monks B, Jin T, Xiao TS, et al. Mouse, but not human STING, binds and signals in response to the vascular disrupting agent 5,6dimethylxanthenone-4-acetic acid. J Immunol. 2013;190:5216-25.

141. Gao P, Zillinger T, Wang W, Ascano M, Dai P, Hartmann G, Tuschl T, Deng $L$, Barchet W, Patel DJ. Binding-pocket and lid-region substitutions render human STING sensitive to the species-specific drug DMXAA. Cell Rep. 2014; 8:1668-76.

142. Vanpouille-Box C, Alard A, Aryankalayil MJ, Sarfraz Y, Diamond JM, Schneider RJ, Inghirami G, Coleman CN, Formenti SC, Demaria S. DNA exonuclease Trex1 regulates radiotherapy-induced tumour immunogenicity. Nat Commun. 2017:8:15618.

143. Vanpouille-Box C, Formenti SC, Demaria S. TREX1 dictates the immune fate of irradiated cancer cells. Oncoimmunology. 2017;6:e1339857.

144. Dasari S, Tchounwou PB. Cisplatin in cancer therapy: molecular mechanisms of action. Eur J Pharmacol. 2014;740:364-78.

145. Ding L, Kim HJ, Wang Q, Kearns M, Jiang T, Ohlson CE, Li BB, Xie S, Liu JF, Stover EH, et al. PARP inhibition elicits STING-dependent antitumor immunity in Brca1-deficient ovarian cancer. Cell Rep. 2018;25:2972-80 e2975.

146. Corbera-Bellalta M, Planas-Rigol E, Lozano E, Terrades-Garcia N, Alba MA, Prieto-Gonzalez S, Garcia-Martinez A, Albero R, Enjuanes A, Espigol-Frigole G, et al. Blocking interferon gamma reduces expression of chemokines CXCL9, CXCL10 and CXCL11 and decreases macrophage infiltration in ex vivo cultured arteries from patients with giant cell arteritis. Ann Rheum Dis. 2016; 75:1177-86.

147. Tan YS, Sansanaphongpricha K, Xie Y, Donnelly CR, Luo X, Heath BR, Zhao X Bellile $\mathrm{E}, \mathrm{Hu} \mathrm{H}$, Chen $\mathrm{H}$, et al. Mitigating SOX2-potentiated immune escape of head and neck squamous cell carcinoma with a STING-inducing nanosatellite vaccine. Clin Cancer Res. 2018;24:4242-55.

148. Spranger S, Sivan A, Corrales L, Gajewski TF. Tumor and host factors controlling antitumor immunity and efficacy of cancer immunotherapy. Adv Immunol. 2016;130:75-93.

149. Gadkaree SK, Fu J, Sen R, Korrer MJ, Allen C, Kim YJ. Induction of tumor regression by intratumoral STING agonists combined with anti-programmed death-L1 blocking antibody in a preclinical squamous cell carcinoma model. Head Neck. 2017;39:1086-94.

150. Wang H, Hu S, Chen X, Shi H, Chen C, Sun L, Chen ZJ. cGAS is essential for the antitumor effect of immune checkpoint blockade. Proc Natl Acad Sci U S A. 2017;114:1637-42.

151. Luo M, Wang H, Wang Z, Cai H, Lu Z, Li Y, Du M, Huang G, Wang C, Chen X, et al. A STING-activating nanovaccine for cancer immunotherapy. Nat Nanotechnol. 2017;12:648-54.

152. Shen J, Zhao W, Ju Z, Wang L, Peng Y, Labrie M, Yap TA, Mills GB, Peng G. PARPi triggers the STING-dependent immune response and enhances the therapeutic efficacy of immune checkpoint blockade independent of BRCAness. Cancer Res. 2019;79:311-9.

153. Ager CR, Reilley MJ, Nicholas C, Bartkowiak T, Jaiswal AR, Curran MA Intratumoral STING activation with T-cell checkpoint modulation generates systemic antitumor immunity. Cancer Immunol Res. 2017;5: 676-84.

154. Harabuchi S, Kosaka A, Yajima Y, Nagata M, Hayashi R, Kumai T, Ohara K, Nagato T, Oikawa K, Ohara M, et al. Intratumoral STING activations overcome negative impact of cisplatin on antitumor immunity by inflaming tumor microenvironment in squamous cell carcinoma. Biochem Biophys Res Commun. 2020;522:408-14

155. Baird JR, Friedman D, Cottam B, Dubensky TW Jr, Kanne DB, Bambina S, Bahjat K, Crittenden MR, Gough MJ. Radiotherapy combined with novel STING-targeting oligonucleotides results in regression of established tumors. Cancer Res. 2016;76:50-61.

156. Lu S, Concha-Benavente F, Shayan G, Srivastava RM, Gibson SP, Wang L, Gooding WE, Ferris RL. STING activation enhances cetuximab-mediated NK cell activation and DC maturation and correlates with HPV(+) status in head and neck cancer. Oral Oncol. 2018;78:186-93.
157. Pei J, Zhang Y, Luo Q, Zheng W, Li W, Zeng X, Li Q, Quan J. STAT3 inhibition enhances CDN-induced STING signaling and antitumor immunity. Cancer Lett. 2019;450:110-22.

158. Wilson DR, Sen R, Sunshine JC, Pardoll DM, Green JJ, Kim YJ. Biodegradable STING agonist nanoparticles for enhanced cancer immunotherapy. Nanomedicine. 2018;14:237-46.

159. Sallets A, Robinson S, Kardosh A, Levy R. Enhancing immunotherapy of STING agonist for lymphoma in preclinical models. Blood Adv. 2018;2:223041.

160. Lemos H, Mohamed E, Huang L, Ou R, Pacholczyk G, Arbab AS, Munn D, Mellor AL. STING promotes the growth of tumors characterized by low antigenicity via IDO activation. Cancer Res. 2016;76:2076-81.

161. Zhong B, Yang Y, Li S, Wang YY, Li Y, Diao F, Lei C, He X, Zhang L, Tien P, Shu HB. The adaptor protein MITA links virus-sensing receptors to IRF3 transcription factor activation. Immunity. 2008;29:538-50.

162. Nowarski R, Gagliani N, Huber S, Flavell RA. Innate immune cells in inflammation and cancer. Cancer Immunol Res. 2013;1:77-84.

163. Ahn J, Xia T, Konno H, Konno K, Ruiz P, Barber GN. Inflammation-driven carcinogenesis is mediated through STING. Nat Commun. 2014;5:5166.

164. Liang D, Xiao-Feng H, Guan-Jun D, Er-Ling H, Sheng C, Ting-Ting W, QinGang H, Yan-Hong N, Ya-Yi H. Activated STING enhances Tregs infiltration in the HPV-related carcinogenesis of tongue squamous cells via the c-jun/ CCL22 signal. Biochim Biophys Acta. 2015;1852:2494-503.

165. An X, Zhu Y, Zheng T, Wang G, Zhang M, Li J, Ji H, Li S, Yang S, Xu D, et al. An analysis of the expression and association with immune cell infiltration of the CGAS/STING pathway in pan-cancer. Mol Ther Nucleic Acids. 2019;14: 80-9.

166. Huang L, Li L, Lemos H, Chandler PR, Pacholczyk G, Baban B, Barber GN, Hayakawa Y, McGaha TL, Ravishankar B, et al. Cutting edge: DNA sensing via the STING adaptor in myeloid dendritic cells induces potent tolerogenic responses. J Immunol. 2013;191:3509-13.

167. Moore E, Clavijo PE, Davis R, Cash H, Van Waes C, Kim Y, Allen C. Established $T$ cell-inflamed tumors rejected after adaptive resistance was reversed by combination STING activation and PD-1 pathway blockade. Cancer Immunol Res. 2016;4:1061-71.

168. Liang H, Deng L, Hou Y, Meng X, Huang X, Rao E, Zheng W, Mauceri H, Mack M, Xu M, et al. Host STING-dependent MDSC mobilization drives extrinsic radiation resistance. Nat Commun. 2017;8:1736.

169. Larkin B, llyukha V, Sorokin M, Buzdin A, Vannier E, Poltorak A. Cutting edge: activation of STING in T cells induces type I IFN responses and cell death. J Immunol. 2017;199:397-402.

170. Cerboni S, Jeremiah N, Gentili M, Gehrmann U, Conrad C, Stolzenberg MC, Picard C, Neven B, Fischer A, Amigorena S, et al. Intrinsic antiproliferative activity of the innate sensor STING in T lymphocytes. J Exp Med. 2017;214: 1769-85.

171. Bakhoum SF, Ngo B, Laughney AM, Cavallo JA, Murphy CJ, Ly P, Shah P, Sriram RK, Watkins TBK, Taunk NK, et al. Chromosomal instability drives metastasis through a cytosolic DNA response. Nature. 2018:553:467-72.

172. Chen Q, Boire A, Jin X, Valiente M, Er EE, Lopez-Soto A, Jacob L, Patwa R, Shah $\mathrm{H}$, Xu K, et al. Carcinoma-astrocyte gap junctions promote brain metastasis by cGAMP transfer. Nature. 2016;533:493-8.

173. Zheng Z, Jia S, Shao C, Shi Y. Irradiation induces cancer lung metastasis through activation of the CGAS-STING-CCL5 pathway in mesenchymal stromal cells. Cell Death Dis. 2020;11:326.

\section{Publisher's Note}

Springer Nature remains neutral with regard to jurisdictional claims in published maps and institutional affiliations. 